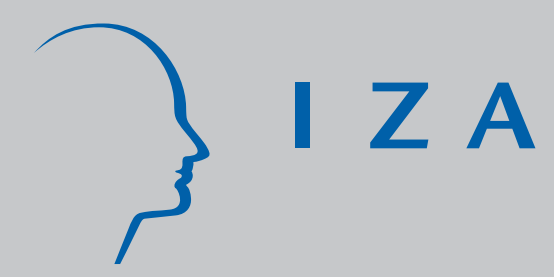

IZADP No. 1589

The Impact of Tax and Transfer Systems on Children in the European Union

Miles Corak

Christine Lietz

Holly Sutherland

May 2005 


\title{
The Impact of Tax and Transfer Systems on Children in the European Union
}

\author{
Miles Corak \\ UNICEF Innocenti Research Centre \\ and IZA Bonn \\ Christine Lietz \\ University of Cambridge \\ Holly Sutherland \\ ISER, University of Essex
}

Discussion Paper No. 1589

May 2005

IZA

P.O. Box 7240

53072 Bonn

Germany

Phone: $+49-228-3894-0$

Fax: +49-228-3894-180

Email: iza@iza.org

Any opinions expressed here are those of the author(s) and not those of the institute. Research disseminated by IZA may include views on policy, but the institute itself takes no institutional policy positions.

The Institute for the Study of Labor (IZA) in Bonn is a local and virtual international research center and a place of communication between science, politics and business. IZA is an independent nonprofit company supported by Deutsche Post World Net. The center is associated with the University of Bonn and offers a stimulating research environment through its research networks, research support, and visitors and doctoral programs. IZA engages in (i) original and internationally competitive research in all fields of labor economics, (ii) development of policy concepts, and (iii) dissemination of research results and concepts to the interested public.

IZA Discussion Papers often represent preliminary work and are circulated to encourage discussion. Citation of such a paper should account for its provisional character. A revised version may be available directly from the author. 


\section{ABSTRACT}

\section{The Impact of Tax and Transfer Systems on Children in the European Union*}

The objective of this paper is to analyze the impact of fiscal policy on the economic resources available to children, and on the child poverty rate. A static microsimulation model specifically designed for the purposes of comparative fiscal analysis in the European Union, EUROMOD, is used to study the age incidence of government taxes and transfers in 2001 in $15 \mathrm{EU}$ countries. Three related questions are addressed. First, what priorities are currently embodied in government budgets across age groups, and in particular to what degree do cash transfer and tax systems benefit children relative to older groups? Second, what fractions of the needs of children are supported by elements of the tax and transfer systems directed explicitly to them? And third, what impact do measures of public resources for children have on child poverty rates?

JEL Classification: $\quad$ 130, I32, I38

Keywords: poverty, children, social policy

Corresponding author:

Miles Corak

Email: Miles.Corak@statcan.ca

\footnotetext{
*This paper was prepared as a contribution to the Innocenti Report Card No. 6 "Child Poverty in Rich Countries 2005," UNICEF Innocenti Research Centre. It has also been published as Innocenti Working Paper 2005-04.

This paper is one of four background papers to UNICEF (2005). It was initiated while Miles Corak was visiting researcher at the UNICEF-Innocenti Research Centre. He is currently Director of Family and Labour Studies at Statistics Canada. The research was funded in part by the Nuffield Foundation and supported by activities within the MICRESA (Micro Analysis of the European Social Agenda) project, financed by the Improving Human Potential programme of the European Commission (SERD-200100099). The authors gratefully acknowledge this support and are also indebted to all other past and current members of the EUROMOD consortium and their colleagues, particularly Olivier Bargain, Frédéric Berger, Tim Callan, Horacio Levy, Manos Matsaganis, Magda Mercader Prats, Håkan Nyman, Kristian Orsini, Carlos Farinha Rodrigues, Stefano Toso, Panos Tsakloglou, Heikki Viitamäki, Klaas de Vos and Gert G. Wagner who commented on a draft version of this paper. However, the results are the sole responsibility of the authors, and do not reflect the views of any of these institutions or individuals. In particular, this applies to the interpretation of EUROMOD results and any errors in its use. EUROMOD is continually being improved and updated, and the results presented here are the best available at the time of writing. The authors also wish to acknowledge with thanks comments on a very early draft from participants at the UNICEF Experts meeting in Florence in June 2004, including particularly Peter Adamson, Jonathan Bradshaw, John Micklewright, Brian Nolan, Mark Pearson, Tim Smeeding, and Anna Wright.

EUROMOD relies on micro-data from twelve different sources for fifteen countries. These are the European Community Household Panel (ECHP) User Data Base made available by Eurostat; the Austrian version of the ECHP made available by the Interdisciplinary Centre for Comparative Research in the Social Sciences; the Panel Survey on Belgian Households (PSBH) made available by the University of Liège and the University of Antwerp; the Income Distribution Survey made available by Statistics Finland; the Enquête sur les Budgets Familiaux (EBF) made available by INSEE; the public use version of the German Socio Economic Panel Study (GSOEP) made available by the German Institute for Economic Research (DIW), Berlin; the Living in Ireland Survey made available by the Economic and Social Research Institute; the Survey of Household Income and Wealth (SHIW95) made available by the Bank of Italy; the Socio-Economic Panel for Luxembourg (PSELL-2) made available by CEPS/INSTEAD; the Socio-Economic Panel Survey (SEP) made available by Statistics Netherlands through the mediation of the Netherlands Organisation for Scientific Research - Scientific Statistical Agency; the Income Distribution Survey made available by Statistics Sweden; and the Family Expenditure Survey (FES), made available by the UK Office for National Statistics (ONS) through the Data Archive. Material from the FES is Crown Copyright and is used by permission. Neither the ONS nor the Data Archive bear any responsibility for the analysis or interpretation of the data reported here. An equivalent disclaimer applies for all other data sources and their respective providers cited in this acknowledgement.
} 


\section{The impact of tax and transfer systems on children in the European Union}

\section{Introduction}

Governments have come under increasing pressure to make explicit and indeed to quantify the impact their budgetary decisions have on particular groups in society. This is the case, for example, with respect to gender and in recent years increasingly so by age. The Convention on the Rights of the Child, which came into force in late 1990, suggests a need to understand the impact of fiscal policy on children, stating in Article 4 that governments will undertake measures to meet the economic, social, and cultural rights of children "to the maximum extent of their available resources” (UNICEF 2002). Understanding this notion in a concrete way is not easy. A first step should be to explore how existing budgetary decisions impact on children. What are the existing priorities embedded in government budgets, and how much emphasis do they place on children and particularly those deemed in some sense to be disadvantaged? Determining just what level of public resources actually are directed to children-as opposed to what level should be-might seem more manageable, but this too is not straightforward.

Governments have perhaps hesitated in responding because providing an accurate description of budgetary impacts is a complex task. One approach to this challenge is put forward in Hodgkin and Newell (2002), and involves enumerating the government programs explicitly directed to children. This has the appeal of being relatively straightforward, but it cannot offer the whole story for a number of reasons. There are often significant gaps between intention and consequence. Governments may make promises and institute programs, but these may never be implemented or spending may be diverted to other purposes in the course of implementation. Further, focusing on a list of programs explicitly labelled as being child orientated does not offer a sense of the magnitude of total spending, of overall budgetary 
priorities, nor of how much consequence these programs ultimately are for children most in need. It also does not recognize that children may benefit from programs not specifically targeted to them, nor that the structure of the tax system also determines the net impact of government budgets. The impact of fiscal policy is mediated through the family and the sharing of resources and burdens within it so that taxes and transfers directed to adults can significantly impact on children. The analysis of South African pension reforms by Duflo (2000) is one striking example. An expansion of pension provisions would at first not appear to be a pro-child policy innovation, but increased spending on grandparents led, in the context of a society in which many live in three generation households, to marked improvements in the health and well-being of children as the extra household income was used to purchase goods of most benefit to them.

A contrasting approach is found in the public finance literature emphasizing the need to examine the life-time incidence of taxes and transfers. This literature stresses the importance of the inter-temporal nature of fiscal policy in determining the incidence of taxes and transfers upon particular age cohorts. The claim that the young or the old are receiving more or less at a particular point of time requires estimates of how much the elderly have received in the past over their entire lives, and how much the young will receive in the future. Auerbach, Kotlikoff, and Leibfritz (1999) in particular have put forward a policy orientated framework for the analysis of generational issues. Their "Generational Accounting” leads to a summary of the priorities, or generational bias, in fiscal policy by estimating the incidence of budgets and government debt on each age cohort in the population as well as future generations. This would seem to address the issue of concern, but the informational requirements of this approach may be daunting and the results can be sensitive to assumptions built into the underlying calculations. In particular, estimating the impact of current policy on the remaining lifetimes of all current and future generations may require forecasts decades 
into the future and a range of what a priori might be a reasonable set of possible discount rates can lead to a rather wide range of results.

However, whatever their relative advantages and weaknesses, both of these perspectives on government budgets do not explicitly detail patterns in the flows of taxes and transfers across age groups and nor do they highlight their impact on the particular group of interest in the context of the Convention on the Rights of the Child, children and particularly poor children. As such the approach applied in the current study is to chart a middle ground in the hope of accomplishing this. The next section describes the possible analytical frameworks and justifies the use of static microsimulation modelling. Our analysis focuses on the EU 15 countries through the use of a particular microsimulation model, EUROMOD, designed explicitly for the comparative analysis of these countries. We use EUROMOD to address the three questions motivating our analysis: (1) what priorities are currently embodied in government budgets across age groups, and in particular to what degree do cash transfer and tax systems benefit children relative to older groups; (2) what fraction of the needs of children are supported by elements of the tax and transfer systems directed explicitly to them; and (3) what impact do measures of public resources for children have on child poverty rates? Sections 3, 4 and 5 address each of these questions in turn, while the final section of the paper concludes.

2. Methods, data, and assumptions

A picture of the relative amount of support targeted on children across countries is easily obtained by comparing statistics on public spending within relevant categories. We offer information of this kind in Table 1 to motivate more fully the reasons for our alternative methodology. The data in this table show OECD estimates for 2001 of public social expenditures as a proportion of GDP. The proportion is lowest for Ireland (13.8\%) and Spain 
(19.6\%) and highest for Denmark (29.2\%) and Sweden (28.9\%). ${ }^{1}$ However, these figures include large components, such as healthcare, public housing and pensions, which are not particularly focused on children. Isolating expenditure on family benefits shows much lower proportions of GDP but, with some exceptions, similar ranking of countries. Family benefits make up a relatively large proportion of spending in Ireland so that rather than appearing as the lowest spender it ranks fourth highest. Spain, Italy, Portugal and the Netherlands all spend least on family benefits. Luxembourg while ranking low on social spending in general is the next to top spender on family benefits. ${ }^{2}$ Generally the Scandinavian countries, UK and Ireland as well as Luxembourg spend most, and the Southern countries together with Netherlands spend least. Focusing on family benefits paid in cash rather than in kind provides yet another ranking. While Denmark spends the most on family benefits, the proportion consisting of cash transfers, at under $40 \%$, is the lowest in Europe. For the majority of countries this proportion is between a half and two-thirds, while for Austria, Belgium, Ireland, Luxembourg and the UK the proportion in cash is over $80 \%$.

The distinction between cash and in-kind benefits is somewhat arbitrary as an account of the extent of support for children. For example, child care cost subsidies will be counted as "in kind” whereas cash benefits to help pay the gross costs will count as "in cash”. On the other hand, it is cash incomes that are measured when assessing the effect of policies on measures of financial poverty or inequality, including some of the indicators adopted by the Laeken European Council in 2001 for monitoring social inclusion in the European Union (European Commission 2001 and Atkinson et al 2002).

\footnotetext{
${ }^{1}$ The very low figure for Ireland is driven by the high level of GDP which is in turn due to very large factor outflows from the Irish economy since the 1980s. See Kelly and Everett (2004).

${ }^{2}$ The relatively low rank on social spending in general for Luxembourg is driven by the high measure of GDP which is influenced by the weight of the cross-border workers in Luxembourg. For example, in 2001 around $37 \%$ of employees were cross-border workers.
} 
Service provision will have a positive effect on quality of life in general and may also have an effect on the incomes of families with children in the longer term. Certainly, to use the same example, support for child care costs will help parents take paid work. But it is useful to distinguish between the direct effects of government cash transfers on current incomes, and the longer term effect of support of all forms on expectations and behaviour. Our focus is on the first issue.

This presentation of OECD statistics is one direct way of approaching the analysis of government budgets for children and is in line with the suggestions in Hodgkin and Newell (2002). However, it raises at least three further issues. First, some social transfers of direct benefit to children may not be labeled as such, housing benefits and social assistance being just two examples. While counting all social spending captures too much that is not relevant, just counting the labeled "family benefits" is too narrow a definition. However expert a categorisation of transfers may be, there are bound to be both "grey" areas and instruments that have multiple functions, but can only be accounted for under one heading or allocated across headings in an arbitrary way. ${ }^{3}$

Second, some of the social transfers benefiting children may be in the form of tax concessions rather than cash payments. In fact, Bradshaw and Mayhew (2003) document that there is an important and growing tendency among many OECD countries to use the tax system to direct support to priority groups. These are not included in the OECD social expenditure statistics, nor is the fact that some social benefits may be subject to tax. ${ }^{4}$ In counting the benefit for children it is the net amount that should be included.

\footnotetext{
${ }^{3}$ An example is the British Working Families Tax Credit which in 2001 was both a benefit for families with children and an in-work top-up. In the OECD SOCEX statistics it is categorised as a family benefit.

${ }^{4}$ OECD is, of course, well aware of the issues. See Adema (1999) and OECD (2004).
} 
Table 1

Social Expenditure on Family Benefits in EU15

\begin{tabular}{|c|c|c|c|c|c|c|}
\hline & & \multirow{2}{*}{$\begin{array}{c}\text { Total Social } \\
\text { expenditure } \\
\text { \% GDP }\end{array}$} & \multicolumn{2}{|c|}{$\begin{array}{l}\text { Expenditure on } \\
\text { family benefits }\end{array}$} & \multicolumn{2}{|c|}{$\begin{array}{c}\text { Expenditure on } \\
\text { cash family benefits }\end{array}$} \\
\hline & & & $\%$ GDP & $\begin{array}{c}\% \text { social } \\
\text { expenditure }\end{array}$ & $\%$ GDP & $\begin{array}{l}\% \text { family } \\
\text { benefits }\end{array}$ \\
\hline Austria & AT & 26.0 & 2.9 & 11.3 & 2.4 & 81.1 \\
\hline Belgium & $\mathrm{BE}$ & 27.2 & 2.3 & 8.5 & 1.9 & 80.9 \\
\hline Denmark & DK & 29.2 & 3.8 & 13.0 & 1.5 & 39.7 \\
\hline Finland & FI & 24.8 & 3.0 & 12.2 & 1.6 & 54.7 \\
\hline France & FR & 28.5 & 2.8 & 9.9 & 1.5 & 52.8 \\
\hline Germany & GE & 27.4 & 1.9 & 7.0 & 1.1 & 59.7 \\
\hline Greece & GR & 24.3 & 1.8 & 7.5 & 1.1 & 60.5 \\
\hline Ireland & IR & 13.8 & 1.6 & 11.9 & 1.4 & 86.4 \\
\hline Italy & IT & 24.4 & 1.0 & 4.0 & 0.6 & 64.9 \\
\hline Luxembourg & LU & 20.8 & 3.4 & 16.5 & 2.9 & 84.0 \\
\hline Netherlands & NL & 21.8 & 1.1 & 5.2 & 0.7 & 63.8 \\
\hline Portugal & PT & 21.1 & 1.2 & 5.5 & 0.7 & 56.7 \\
\hline Spain & $\mathrm{SP}$ & 19.6 & 0.5 & 2.6 & 0.3 & 59.8 \\
\hline Sweden & SW & 28.9 & 2.9 & 10.1 & 1.8 & 61.0 \\
\hline United Kingdom & UK & 21.8 & 2.2 & 10.2 & 1.9 & 86.3 \\
\hline
\end{tabular}

Source: OECD (2004), Social Expenditure Database (SOCX, www.oecd.org/els/social/expenditure).

Third, social transfers intended for another group may indirectly benefit children if they share incomes within the same household (or indeed, within extended families, across households). In this sense there are two distinct issues: the effect of the tax-transfer system on the income of households with children, and the effect of transfers and tax concessions received by households by virtue of the presence of children.

When considering the incidence of public spending on children we must also consider how the effects are mediated by the family, and recognize that this mediation varies across countries. Children may be co-resident with people who receive state incomes by virtue of their own situation — for example, old age or unemployment—rather than the presence of children. These people may include, as well as the child's parent(s), other adults such as adult siblings or grandparents. Furthermore, both the immediate family and the wider household influence 
spending decisions, whether the income is received in the form of benefits for children or through other means. Not only may a benefit labeled for the child not be spent on goods and services for the child, but more broadly it is difficult to make generalities about the allocation of income within the household.

Our analysis adopts two alternative perspectives. One is to make the conventional assumption that resources are shared equally and that the benefit from income is independent of the source of the income. On this basis we ask: how much does state spending on cash transfers and tax concessions benefit children relative to older age groups? The other is to focus on the state payments that are made because of the presence of children and to ask: what impact do child-contingent transfers and tax concessions have on the incomes of households with children? Neither of these questions can usefully be answered in isolation or in absolute terms. In a cross-country perspective, however, they allow us to assess the relative priorities and performance of each tax-transfer system in its context.

There are three possible approaches to examining the effects of tax and transfer systems for children in comparative perspective, all of which occupy the middle ground between a descriptive analysis of programs and that based upon life-time incidence calculations like Generational Accounting. Each has its own advantages and disadvantages. The first is to calculate transfer entitlements and tax liabilities for a set of constructed "model families” who represent the family types of interest, as for example in Bradshaw and Finch (2002) and OECD (2004). The second is to use information from micro datasets on households that are broadly representative of the national populations. To the extent that the relevant income components are recorded in these datasets, the share of transfers and taxes of different types in household income can be calculated for each household and the information assembled across households to enable exploration of differences and similarities of impact across household characteristics. Two recent examples are Chen and Corak (2005), and Smeeding (2003). The third method 
combines features of both of these, using a tax-benefit microsimulation model. Such models calculate disposable income for each household in a representative set of micro-data, usually derived from surveys. The calculation of household disposable income is made up of elements of gross original income taken (or imputed) from the original data combined with elements of income — taxes and transfers — that are simulated by the model. Simulated information on incomes is used in the place of information provided by survey respondents.

We adopt this third approach. The advantage of using simulated information is that more detail can be identified for each component of income and for interactions between them. ${ }^{5}$ The main disadvantage of static microsimulation in this context is the fact that some assumption must be made about benefit take-up and tax evasion. The use of calculated entitlements and liabilities ignores the fact that in some countries there are identified problems with incomplete take-up of means-tested transfers, and in some countries there is a known problem with tax evasion. Correcting for such departures from the rules is not straightforward or simple to do in a way that is comparable across countries because the reasons for non-take-up depend on the form and administration of each tax or transfer and are therefore country-specific. ${ }^{6}$ As such an analysis based on this approach offers, in a sense, a best case scenario for each country.

The same problems apply to the "model family" approach, although it is possible to do a set of calculations for each family based on assumed forms of take-up/evasion as well as a set using full compliance. This illustrates the effect of non-compliance on particular family incomes but does not provide information about its significance in practice. The key advantage of the model family approach is that all the details of the social transfer system can in principle be incorporated. All that is required are assumptions about reasonable or appropriate values for

\footnotetext{
${ }^{5}$ Many household income surveys do not collect the information necessary to calculate income from each separate source, gross of income taxes and social contributions. For example, the European Community Household Panel (ECHP) aggregates sources of transfer income together under functional headings and provides estimates of non-transfer income net of taxes and contributions.

${ }^{6}$ See Hancock et al (2004) for a discussion of the different factors that affect three separate benefits within one country.
} 
each relevant characteristic for the family. For example, entitlement to a child disability benefit could be calculated based on an assumption about the nature and degree of disability of the child concerned. Such information is rarely available in household income surveys.

The main disadvantage of the approach is that the results cannot be said to take their context into account. They are useful for comparing the effects of the system on families of different types within a country, and on families of the same type across countries or through time. But they do not take into account the relative importance of each family type across countries (or through time), nor other types of families not considered. In particular, complex three-generation families or those with non-standard (but not necessarily unusual) combinations of income source are typically not covered. Attempts can be made to weight the set of model families to provide "synthetic" population results. But almost by definition the full range of relevant characteristics cannot be covered adequately. To be tractable, weighting regimes can only control for a limited set of characteristics and in cross-national perspective it is problematic to decide on the set that is the most important.

Our analysis makes use of EUROMOD, the tax benefit model for all 15 countries that made up the European Union prior to the enlargement of May 2004. ${ }^{7}$ EUROMOD is used in two distinct ways. First, it provides a database for descriptions of how existing tax and benefit systems have an impact on incomes of children and their families in 15 countries. This allows us to address questions dealing with the priorities embedded in existing tax-transfer projects, and specifically just how the current structure of government budgets influence the economic resources available to children relative to older age groups. The intention is to offer policy makers and advocates as clear and complete a picture of the age-incidence of taxes and transfers. This falls short of calculating the life-time incidence of taxes and transfers, but is a necessary first step to such calculations while at the same time making clear-in the here and

\footnotetext{
${ }^{7}$ See Immervoll et al. (1999) and Sutherland (2000) for general descriptions. Sutherland (2001) provides a description and discussion of technical issues. The version of EUROMOD used in this paper is 28A.
} 
now - the nature and magnitude of the impact of taxes and transfers on children and others in the population. Ermisch (1989), Hicks (1998), and particularly Lee (2003, 1994) are examples of similar research.

Secondly, we use EUROMOD to identify the net public spending (including tax concessions) households receive by virtue of the presence of children. ${ }^{8}$ This is obtained by recalculating household incomes as though the children were not there. In other words, this "what if" approach allows us to examine what the circumstances of the household would be in the absence of child-contingent state support. This requires the unique power of a microsimulation tax-benefit model to re-estimate taxes and transfers, and produces results recognizing that some child-contingent income components are substituted for by other components in the absence of children. It calculates the net effect on household income due directly to the presence of children. ${ }^{9}$

The datasets that are used in the current version of EUROMOD are shown in Appendix 1. The choice of dataset is based on judgement of national experts of the most suitable dataset available for scientific research. Throughout we consider policies as they existed on June $30^{\text {th }} 2001 .^{10}$ In most cases the input datasets refer to a period a few years prior to this and the original incomes derived from them are updated to this date. This process relies on indexing each income component (that is not simulated) by appropriate growth factors, based on actual changes over the relevant period. ${ }^{11}$ In general no adjustment is made for

\footnotetext{
${ }^{8}$ So the issues not addressed explicitly here include (a) the impact of non-cash transfers or indirect taxes and (b) identification of how child-contingent financial payments to parents affect child welfare (the "within household" incidence issue).

${ }^{9}$ The alternative, using micro-datasets directly, would be to itemise the income components due to children. Apportionment of components partly for children and partly for adults could only be arbitrary and approximate. The effect of adult substitutes would not be captured. The value of tax concessions (such as child tax credits) and the effect of the taxation of benefits could only be approximated.

${ }^{10}$ It is necessary to specify a precise date because the timing within the year of regular uprating and other adjustments to tax-transfer systems varies across countries.

${ }^{11}$ This process is documented in EUROMOD Country Reports. See www.econ.cam.ac.uk/dae/mu/emodcty.htm
} 
changes in population composition. ${ }^{12}$ Results are thus in some sense a hybrid of 2001 and the data year.

The basic output from EUROMOD is household disposable income and the micro-level change in the value of this as a result of changes to any of the determinants of direct personal taxes including contributions or cash transfers: for example, policy rules, levels of original income, household composition. EUROMOD has been designed to maximise comparability across countries through two mechanisms: (1) by harmonising output income concepts and classificatory variables; ${ }^{13}$ and (2) by offering the user a very wide range of choice over assumptions and definitions. Typically, national models "hard wire” national assumptions about such things as the definition of a child. This inhibits comparable analysis across models (countries) and is the main justification for the original decision to construct EUROMOD as a model with comparability as its main purpose (Callan and Sutherland 1997).

Our analysis is based upon the following definitions and assumptions.

- Children are defined as individuals younger than 18 years. ${ }^{14}$

- We generally assume that income is shared within the household such that household disposable income can be used to indicate the economic well-being of each individual within the household. When comparing across households incomes are equivalised using the square root of household size. ${ }^{15}$ Generally, the individual is taken as the unit of analysis. So our focus is on each child, rather than on parents or families containing children.

\footnotetext{
${ }^{12}$ One exception is the case of Ireland, where weights adjust to the 2001 population.

${ }^{13}$ Some national peculiarities remain. These are noted where relevant. In particular the unit of income aggregation for Sweden is the narrow family unit (single person or couple plus children aged under 18) whereas for other countries the data allow us to use the wider household - all people living in one dwelling and sharing some of the costs of living. The reference time period in Ireland and the UK is the current month whereas for all other countries it is the previous year. (In all cases incomes are reported here in annual terms.)

${ }^{14}$ Note that while this is in accord with the definition in the Convention on the Rights of the Child it diverges from that used in many national tax and transfer rules and regulations, as would any common definition. In calculating taxes and transfers the appropriate child definitions are used. In evaluating the effect on children, the simple common age cut-off is applied.
} 
- Household disposable income is defined as original income added up over each household member plus between-household transfers (maintenance and alimony), minus taxes (income tax, social contributions and other direct personal taxes) plus cash transfers. Cash transfers are assumed to include public pensions in payment but do not include regulated private pensions that may substitute for these. ${ }^{16}$ Non-cash benefits are not included.

- Poverty is defined as living in a household with equivalised household disposable income below $50 \%$ of the median (where the median is calculated across individuals). ${ }^{17}$ The child poverty rate is defined as the proportion of all children living in poor households.

- Where currency amounts are reported these are in PPP-adjusted Euro using OECD conversion factors for 2001.

- We do not explicitly model non-take up of benefits or tax avoidance or evasion. Thus it is assumed that the legal rules apply and that the costs of compliance are zero. This can result in the over-estimation of taxes and benefits. ${ }^{18}$

This way of proceeding is in accord with a wide body of international research on the topic of income comparisons and poverty, as evidenced for example in the Luxembourg Income Study project and the recommendations of the report of the Expert Group on Household Income Statistics (2001). This said it should also be noted that the use of the so-

\footnotetext{
${ }^{15}$ Appendix 3 provides some of the key figures in this paper using the modified OECD equivalence scale, as recommended by Eurostat.

${ }^{16}$ Contributory pensions are included as "transfers" even though a large part of their role is intra- rather than inter- personal redistribution. We justify their inclusion on the basis that this study is not simply about redistribution as such, but is also concerned with the priority given to children over other groups. Contributory child benefits - where they exist - are included in transfers, along with contributory pensions.

${ }^{17}$ Appendix 3 provides some poverty estimates using 60\% of the median as the cut-off, as recommended by Eurostat.

${ }^{18}$ It can also result in the under-estimation of poverty rates although this depends on the relationship between the level of income offered by the benefits and the poverty line (potential claimants may be poor whether or not they receive the benefits to which they are entitled). A comparison of poverty rates estimated using simulated incomes from EUROMOD, with those calculated directly from survey data by the OECD or available through the Luxembourg Income Study is provided in Appendix 2.
} 
called "head count ratio" (the number of children who are poor divided by the total number of children) as an indicator of poverty has its limitations. ${ }^{19}$ This measure gives equal weight to all individuals below the poverty threshold and explicitly assumes that poverty is a discrete event associated with being above or below a given line. Someone with household income one Euro below the threshold is given the same consideration as someone at the very bottom of the income distribution. In part, the appropriateness of this assumption will depend upon the theoretical perspective used. For example, Atkinson (1998) states a rights perspective suggests the headcount ratio is, in fact, the appropriate statistical indicator. A "right' is an either-or concept: it is either being respected or it is being violated. In his view an indicator based upon a view that poverty is a discrete condition reflecting less than a minimum acceptable income might be viewed as appropriate. But other interpretations, and indeed other interpretations based upon a rights perspective, might quite reasonably suggest that individuals below the poverty threshold should not be weighted equally. The situation of those very much below the poverty line might in some sense matter more than those just below. The headcount ratio could after all be lowered by taking enough money from the very poorest and transferring it to those hovering just below the poverty line and moving them just above. This sort of policy, which would lower the headcount ratio, would not have a good deal of appeal to most observers. While conscious of these limitations we rely on the headcount ratio in part because of its intuitive appeal within a rights framework, and the continued relevance it has in public policy as a tool for communicating to a broader public. At the same time we also introduce evidence on another measure that gives more weight to those further below the poverty line.

Child poverty rates based upon the headcount ratio are provided in Figure 1 for each of the 15 countries under study. These are contrasted with the overall national poverty rates, the

\footnotetext{
${ }^{19}$ The following discussion is drawn from Chen and Corak (2005).
} 
countries being ranked in ascending order of their child poverty rate. As might be expected, there is a strong relationship between low overall poverty and low child poverty. ${ }^{20}$ In five countries the child poverty rate is below five percent: Sweden, Denmark, Finland, Austria and Belgium. Further in all of these cases the poverty rates for children are lower than that for the whole populations, even though these rates are also low by international standards. Child poverty rates range from five to less than $10 \%$ in four countries-Luxembourg, Germany, the Netherlands and France-and are higher than the overall rate. The chances that children live in poverty are significantly greater than for the average member of the population in Luxembourg and the Netherlands. The remaining six countries all have child poverty rates which are above $10 \%$, and with the exception of Greece, higher than the national average. It appears from this that countries with low poverty rates give special priority to the protection of children. However, the effect of tax and transfer systems on children depends not only on the design of the system itself but also on the position of the family in the society and economy. For example, the effect on children of benefits targeted on low income households will be small if households with children tend not to be concentrated among those with low market incomes. So it may be the case that children in these low poverty countries require less protection because of the better economic situation of their parent(s).

\footnotetext{
${ }^{20}$ Of course the ratio of all- to child- poverty will be sensitive to the equivalence scale used, as well as to the particular poverty line. Appendix 3 repeats this analysis using the Eurostat-recommended scale and risk-ofpoverty threshold.
} 
Figure 1

Child poverty rates compared with overall poverty rates in the EU 15 countries, 2001

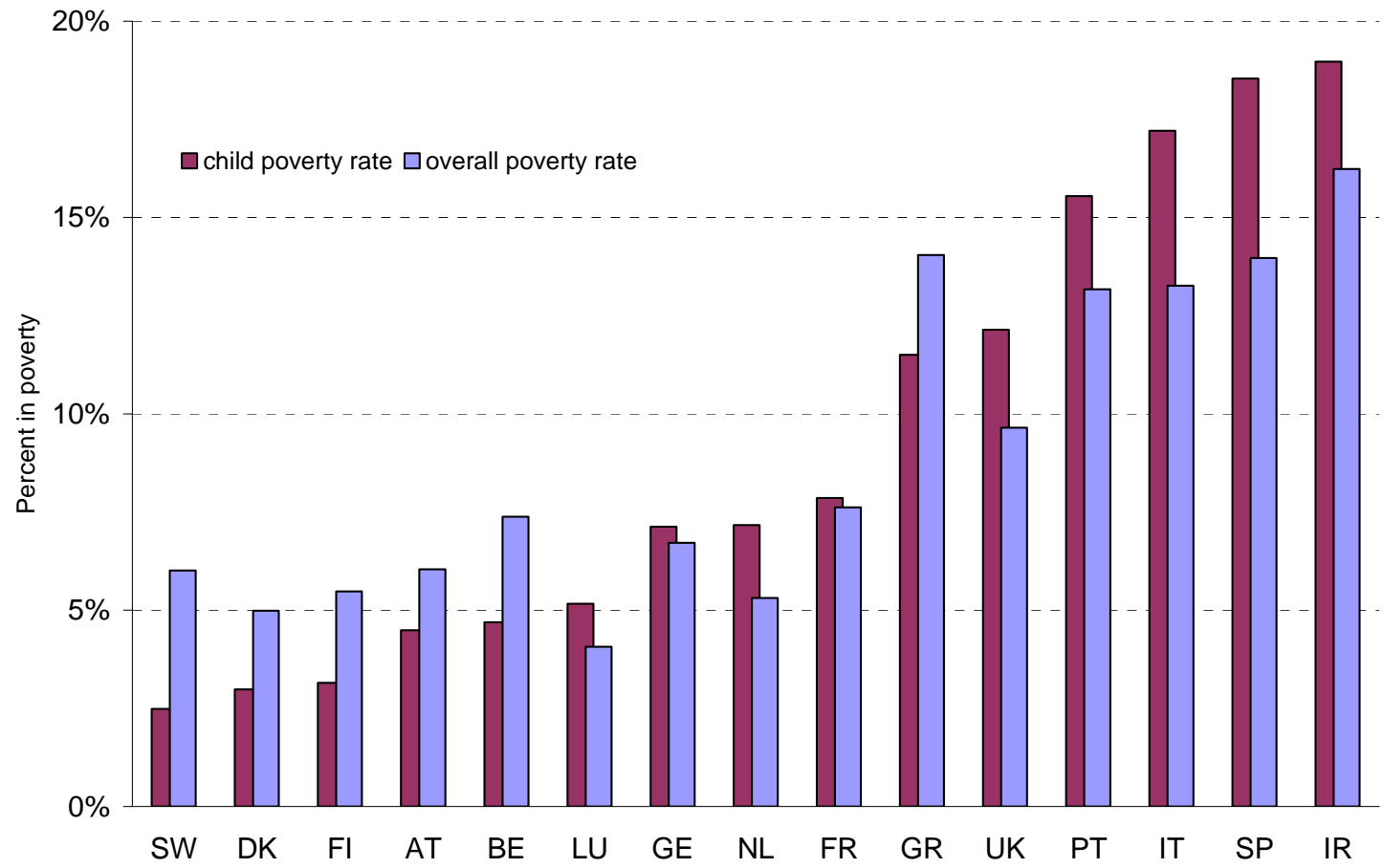

Source: Calculations by authors using EUROMOD version 28A.

\section{The age incidence of tax and transfer systems}

In order to describe the priority given to children in the tax and transfer system we start our analysis with EUROMOD by considering the amount of state transfers received and the amount of taxes paid by each person's household according to the age of the person. This calculation effectively assumes sharing of taxes and transfers within the household so that, for example, a child would benefit from the pension income of its co-resident grandparent, and the grandparent from any child benefit paid on behalf of the child. Once again the results are presented for countries with the lowest to the highest child poverty rates. The left-hand panels of Figure 2 plot transfers received and taxes paid, as proportions of household disposable 
income, averaged over all people within the age ranges shown. The 15 countries are presented in three groups: those with child poverty rates less than five percent in Figure 2a; those with rates between five and 10\% in Figure 2b; and those with rates higher than 10\% in Figure 2c. Further, the charts in the right hand panels show the same information for those with incomes below the poverty threshold. ${ }^{21}$

Together these charts provide a country-by-country portrait of the priority accorded to children through the structure of government budgets, and as mediated by family structure and labour market behaviour. As an example, the two graphs for Denmark show that children under the age of five receive approximately $30 \%$ of 'their' income from government sources, and that for children of low income families this proportion rises to almost $80 \%$. In France, the equivalent figures are closer to $15 \%$ and $60 \%$, and in Greece $5 \%$ and $15 \%$. Further the slopes of the lines indicate the age preferences embodied in the tax and benefit systems. In Denmark there is, for example, a drop off in benefits in moving from the situation of preschool age children, to school age children, to those in their teens, and then an increase for groups between 18 and 29. This pattern is even more notable for those in low income. In France the benefit structure is clearly universal showing very little change with age, while in Greece benefits increase with age in a way that suggests children receive the least.

\footnotetext{
${ }^{21}$ In some countries, particularly those with low poverty rates or small populations, the sizes of the data samples for some age groups are not large enough for the estimates to be considered statistically significant. (This applies particularly to Belgium, Denmark, Ireland, Luxembourg and the Netherlands.) Nevertheless the general shape of the age profiles can be considered as having a valid story to tell.
} 


\section{Figure 2a}

The distribution of taxes and transfers across age groups: countries with child poverty rates lower than five percent
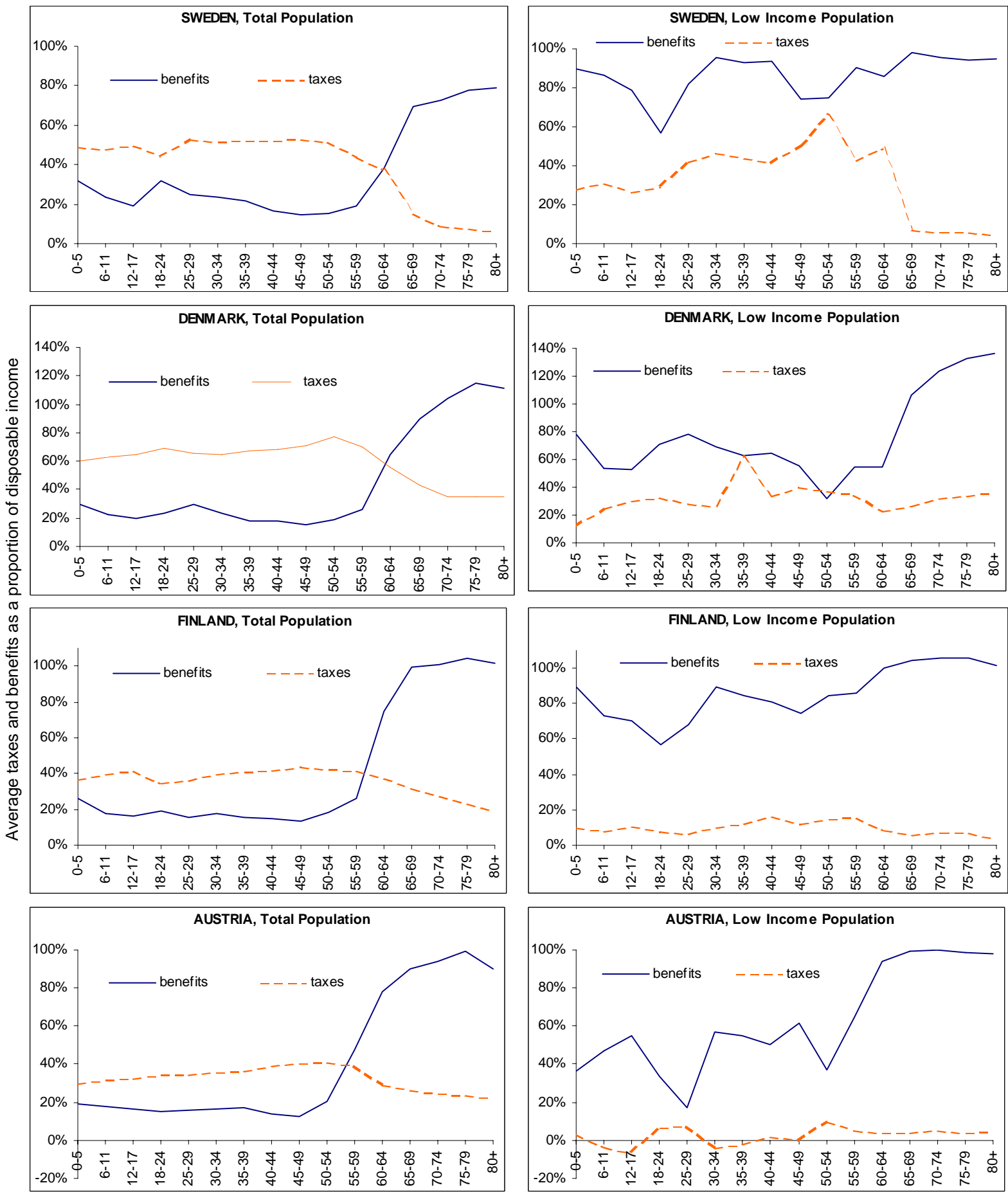

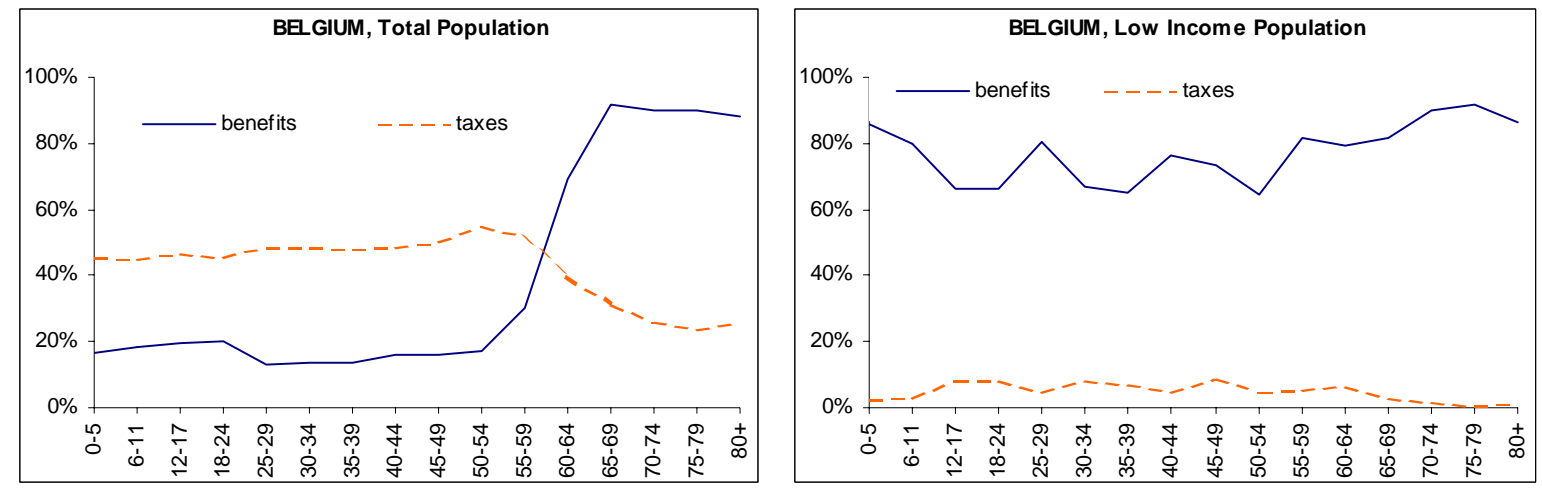

Source: Calculations by authors using EUROMOD version 28A.

Notes: "taxes" include employee and self-employed social contributions; "benefits" include public pensions. 


\section{Figure $2 b$}

The distribution of taxes and transfers across age groups: countries with child poverty rates between five and ten percent
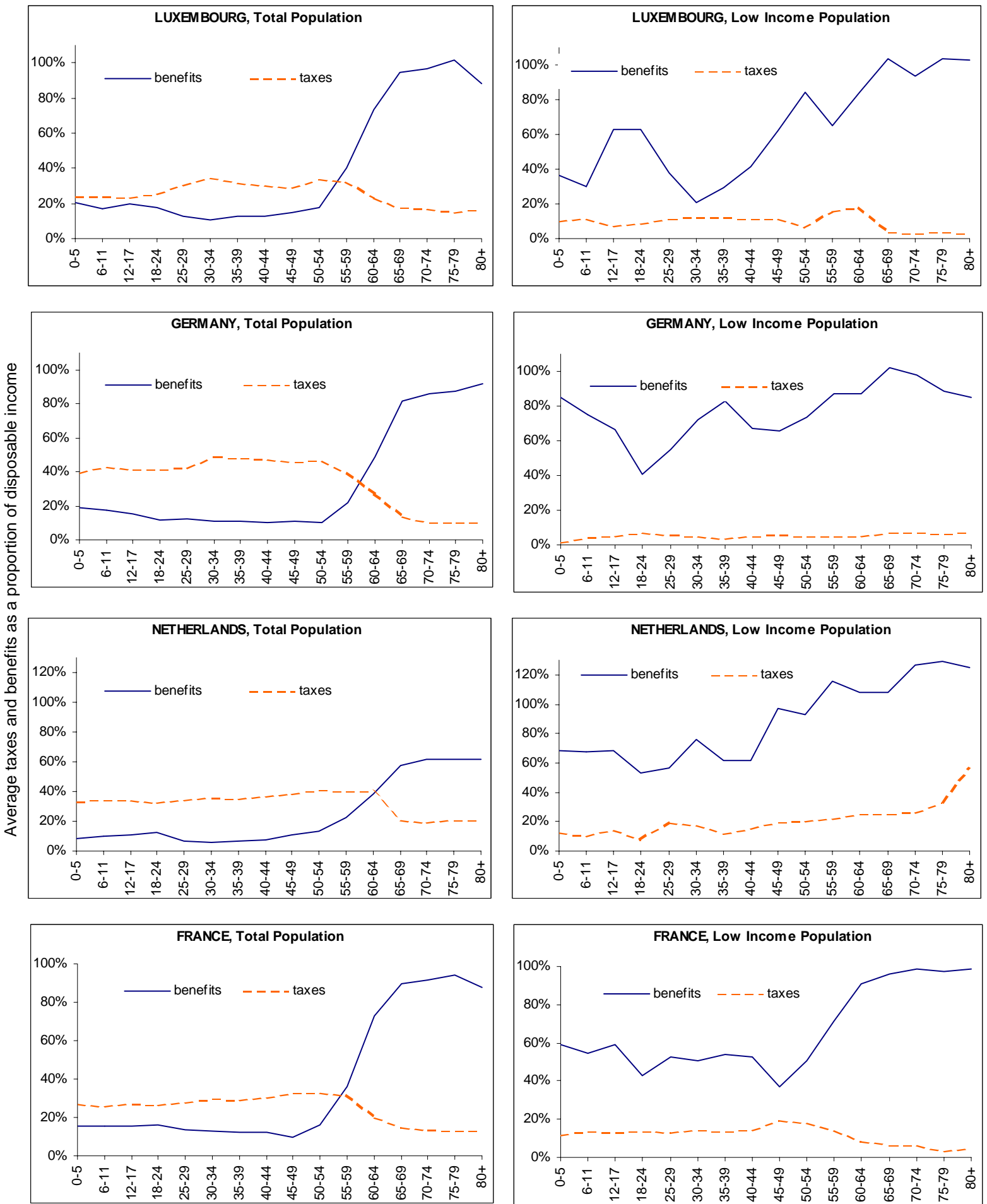

Source: Calculations by authors using EUROMOD version 28A.

Notes: "taxes" include employee and self-employed social contributions; "benefits" include public pensions. 


\section{Figure 2c}

The distribution of taxes and transfers across age groups: countries with child poverty rates greater than ten percent
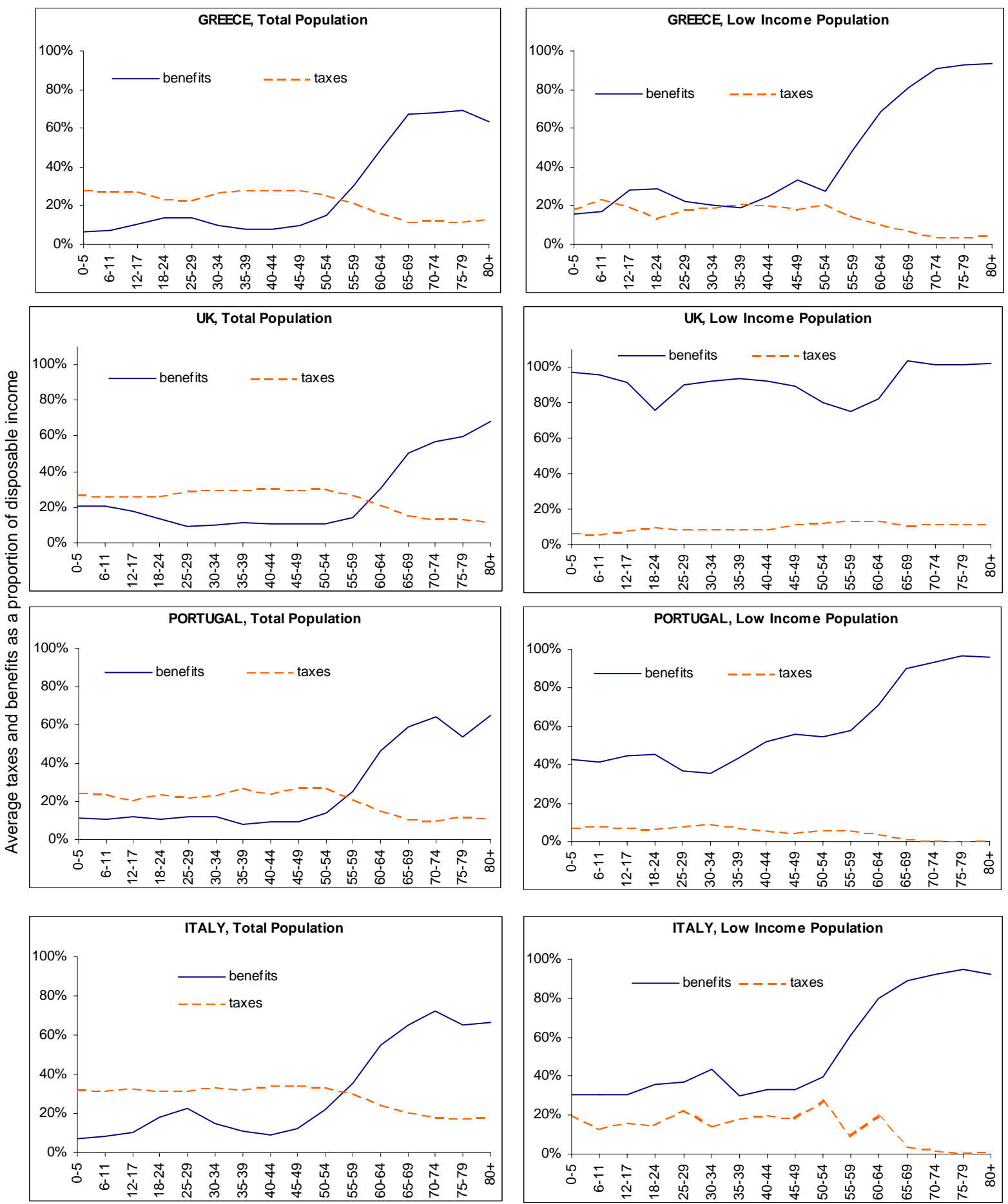

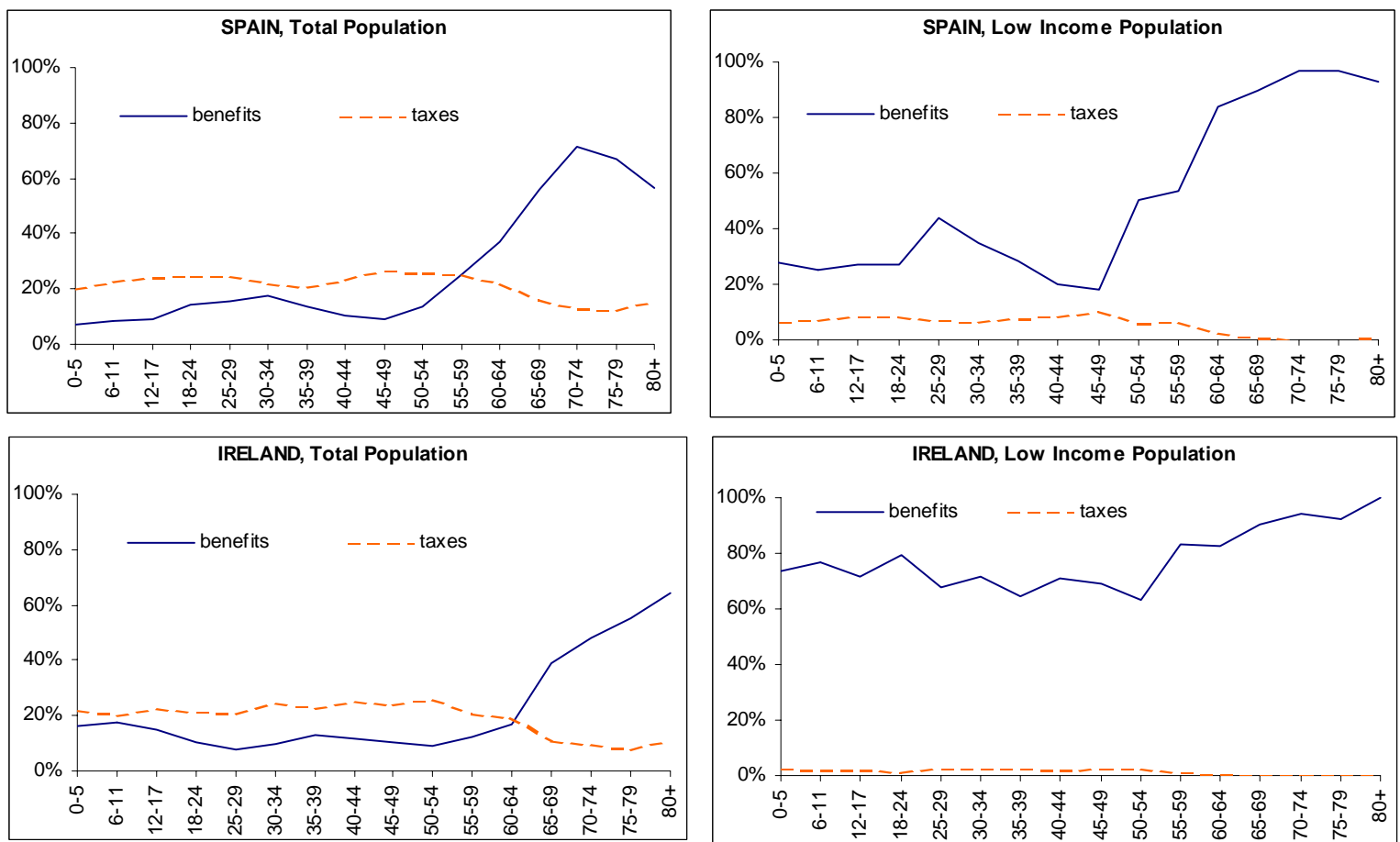

Source: Calculations by authors using EUROMOD version 28A.

Notes: "taxes" include employee and self-employed social contributions; "benefits" include public pensions. 
Some common features are noticeable in all countries. First, the proportion of income made up by transfers rises sharply at around age 65, and even younger in some countries, because of public pension provision. In many countries public pension income makes up all or nearly all of the income of the elderly. Taxes generally decrease as a proportion of income for the elderly, a direct consequence of generally lower incomes in old age combined with tax systems that are progressive and/or contain concessions for pensions or the income of older people more generally. ${ }^{22}$ For younger age groups, benefits are a smaller proportion of income and a flat U-shape is observable in many countries, with children receiving a higher proportion of household income from transfers than do the middle-aged or young adults. This is not universally the case: transfers are a smaller proportion of household income for children than for young adults in Italy, Spain and Greece. In all countries the average size of transfer income is smaller than the average tax paid until a cross-over point at around pension age. The fact that the discrepancy between aggregate tax payments and benefit receipts is large in some countries and small in others is not a reflection of different public deficits: instead it is the result of the extent to which countries rely on the elements of income that we measureincome taxes, employee and self-employed contributions and cash benefits—rather than say indirect or corporate taxes, employer contributions or non-cash benefits.

So it is the shape of the curves that is of interest, rather than their relative levels. A few countries exhibit an apparent preference for younger children over older children in their transfer systems: Sweden, Denmark, Finland, Luxembourg, and Germany. Generally taxes appear flat across pre-elderly age groups or exhibit a very shallow inverted U-shape. However, since the direct tax system is to some extent progressive in all 15 countries $^{23}$ part of the effect may be due to the middle-aged having higher tax burdens because of higher incomes as well as their missing out on specific tax concessions targeted on the young and the

\footnotetext{
${ }^{22}$ For an analysis of the taxation of replacement incomes in EU15 using EUROMOD see Verbist (2005).

${ }^{23}$ See Verbist (2004) for an analysis using EUROMOD.
} 
old. Similarly, transfers may make up a larger share of incomes at older and younger ages because other incomes are lower at these points in the lifecycle, as well as because transfers are more generous for children and the elderly, regardless of income. ${ }^{24}$ Contributory factors are the extent to which the parental incomes are at their peak during their child-raising years or, conversely, are reduced due to the withdrawal or partial withdrawal from the labour market at this period in the lifecycle.

Preference for children in transfer systems is only a little more obvious when considering the population with incomes below the poverty threshold. Low income children receive from 60 to $80 \%$ of their income from the transfer system in all countries with child poverty rates below ten percent. The proportion is much lower, in the range of 20 to $30 \%$, in countries with higher child poverty rates with the important exceptions of the UK and Ireland where between 80 and $100 \%$ of disposable income is made up of transfers. In many of these countries those in their 50s receive a higher proportion of disposable income from state transfers than those younger than 18. This is most notably the case in Spain, but also in Greece, Portugal and Italy. All these countries have child poverty rates greater than ten percent. This pattern of greater support to those in their 50s than to early childhood is also evident in Luxembourg, the Netherlands, as well as France and Austria. In all these countries this is explained by relatively generous pension and early retirement benefits, to which recipients have contributed earlier in their working lives.

With the exception of Austria there is a strong preference for children in the transfer systems of the countries with the lowest child poverty rates, and also, though to a lesser extent in Belgium. Germany also stands out among the countries in Figure $2 \mathrm{~b}$ as also having a strong preference for the youngest low income children, with the proportion of income made up of

\footnotetext{
${ }^{24}$ Admittedly several factors could be at play that will vary from country to country according to the structure of their transfer schemes. Benefits could be higher for first children, also they vary by family size and large families are more likely to have younger children.
} 
transfers falling sharply with age and particularly after 17 years of age. In the UK and Ireland all low income individuals receive a high fraction of transfer income, but this does not appear to be strongly related to age. This suggests a very high degree of targeting of benefits according to income and little reliance on market sources.

This raises a number of concerns that are important to bear in mind when interpreting the patterns shown in Figure 2. These can be explained not just by the extent to which tax and transfer systems are targeted by age. Differences across countries can also be explained by: how original income, and sources of income vary with age; and how people of different ages are grouped together in households. These factors may vary across countries. For example, very young children may appear to have higher transfer incomes simply because their mothers are not fully active in the labour market. A benefit which is payable regardless of the child's age becomes a higher proportion of household income if the mother has low or zero earnings than if she is in full time work. Variation in labour market participation by parents may have as much impact on the age profiles as the tax and transfer systems themselves. In some cases there may be an interaction between the two in a way that illustrates the inherent trade-offs in the design of social policy. Highly targeted social expenditures may focus government resources on those most in need, but may result in beneficiaries having little to gain by moving into work. Universally provided benefits avoid this trap.

The information in Table 2 examines whether the presence of other people, apart from the child's parent(s), in the household makes a difference to the relative importance of taxes and transfers. This shows whether the children and their parent(s) are sharing the household, and by assumption incomes, with other people. Since poverty is measured according to household income, the contribution these other people may make to household income and to the needs will have an impact on poverty. In addition, the presence of other adults who are not adult siblings of the children on which we focus, indicates the likely presence of grandparents 
and the possibility that pensions make up part of household income, and particularly to the “transfers” variable used in Figure 2.

Table 2 shows that the proportion of children living in households with only their parents and siblings under the age of 18 varies from 93\% in the Netherlands to 63\% in Spain and Portugal. ${ }^{25}$ Underlying this variation are different patterns of co-residence with adult siblings and with other adults. ${ }^{26}$ The highest rates of co-residence with adult siblings occur in Spain (20\%) and Ireland (19\%). The highest rates of co-residence with other adults occur in Portugal (24\%) and Spain (18\%). While a large group of countries have rates of co-residence with adult siblings of between 10 and 13\% (Portugal, Greece, Austria, France, Germany, Belgium and Denmark) most of these countries have relatively low rates of co-residency with other adults. Portugal is the exception. Low rates of co-residency of both types are observed in UK (9\% for adult siblings; 6\% for other adults), Finland (10\% and 2\%) and especially the Netherlands (6\% and 1\%).

From the evidence in Table 2 it is clear that the scope for the sharing of incomes from many sources to either supplement or substitute for state transfers varies across countries . Indeed, adult children (those 18 and older) may be net contributors to household income or net users of household resources. Similarly, the incomes of the other adults (mainly pensions) may be effectively helping to support children, or the flow of support may be in the other direction from the children's parental income. Cross-country variation in such factors should be recognized before drawing firm conclusions from the information in Figure 2.

\footnotetext{
${ }^{25}$ We omit Sweden from this discussion because the household is defined in the EUROMOD database as the inner family only, so by construction no children live in households with adults apart from their parents.

${ }^{26}$ Households containing both adult siblings and other adults are included in the latter group.
} 
Table 2

The proportion of children in EU15 sharing their household with adults in addition to their parents

\begin{tabular}{|c|c|c|c|c|c|c|c|c|c|c|c|c|c|c|c|}
\hline & \multicolumn{5}{|c|}{$\begin{array}{c}\text { Countries with child poverty rates less } \\
\text { than } 5 \%\end{array}$} & \multicolumn{4}{|c|}{$\begin{array}{r}\text { Countries with child poverty } \\
\text { rates between } 5 \% \text { and } 10 \%\end{array}$} & \multicolumn{6}{|c|}{$\begin{array}{c}\text { Countries with child poverty rates greater } \\
\text { than } 10 \%\end{array}$} \\
\hline & SW* $^{*}$ & DK & FI & AT & $\mathbf{B E}$ & $\mathbf{L U}$ & GE & NL & FR & GR & UK & PT & IT & SP & IR \\
\hline $\begin{array}{l}\text { No adults other than parents in the } \\
\text { household }\end{array}$ & 100.0 & 88.1 & 88.5 & 76.6 & 87.5 & 82.6 & 85.8 & 92.9 & 84.2 & 74.9 & 85.7 & 63.0 & 75.3 & 62.8 & 70.8 \\
\hline Individuals aged $18+$ in the household & 0.0 & 10.7 & 9.8 & 10.4 & 10.6 & 9.1 & 11.8 & 6.4 & 12.6 & 11.0 & 8.6 & 13.0 & 15.9 & 19.5 & 18.6 \\
\hline Other adults in the household & 0.0 & 1.2 & 1.7 & 13.0 & 1.9 & 8.3 & 2.4 & 0.7 & 3.2 & 14.1 & 5.8 & 24.0 & 8.8 & 17.6 & 10.5 \\
\hline Total & 100.0 & 100.0 & 100.0 & 100.0 & 100.0 & 100.0 & 100.0 & 100.0 & 100.0 & 100.0 & 100.0 & 100.0 & 100.0 & 100.0 & 100.0 \\
\hline
\end{tabular}

Source: Calculations by authors using EUROMOD version 28A.

Notes: No other adults other than parents in household: household consists of parent(s) and their children younger than 18 only

Individuals aged 18+ in household: household consists of only parent(s), their children younger than 18 and at least one child aged 18 or older

Other adults in the household: other people than parent(s) and their children live in household (e.g. grandparents)

* for Sweden the household is defined as the inner family 


\section{Child-contingent components in tax-transfer systems}

To give more focus to the extent of support for children we examine exclusively that part of social transfers contingent on their presence in the household, which we refer to as being “child-contingent”. This corresponds to the extra income the household receives from the state because of the presence of children, or the "net child-contingent" incomes, and involves the re-calculation of taxes and transfers as though there were no children. In common with analyses that compare indicators of income and poverty before and after benefits (Chen and Corak 2005; Dennis and Guio 2004; Heady et al., 2001) we make no adjustment for changes in behaviour that may take place if there were suddenly no income associated with the child, or indeed no child. As such the "no children” counterfactual is purely a descriptive or accounting device intended to identify the extent to which the presence of children is directly recognised through the tax and transfer systems.

This calculation is not the same as simply counting up the value of child and family benefits. In many systems alternative benefits would to some extent substitute for these income sources if they did not exist, or if the children were not present. Alternative housing benefit schemes may exist for parents and non-parents; social assistance benefits may "fill the gap” left by family benefits. Indeed some child-related components may be taxable and in this case their absence would result in a reduction in tax liability. Generally, the removal of tax concessions for children will result in taxes rising. EUROMOD re-calculates liabilities and entitlements and thus measures the net effect of child-contingent tax-benefit components.

The definition of the components which can be considered child-contingent needs to be clarified in two respects. First, within this framework the inclusion of maternity, paternity, and parental leave payments would depend on whether these are considered to be for parent, or for the child. We do not include maternity/paternity/parental benefits but do include 
payments made for the costs of a newborn child. ${ }^{27}$ It must be recognised that this excludes a key component of the approach to family support in the Scandinavian countries. These countries provide a large degree of support through facilitating mainstream labour market participation by parents, rather than targeting children themselves with cash benefits. Our approach of highlighting child-contingent payments has the effect of diminishing the apparent scale of support to families in Sweden, Finland and Denmark in two ways: directly by not counting the cash value of parental benefits and indirectly by not accounting for the implicit value of supporting parents to maintain labour market activity.

Payments made on a per person basis, regardless of age also raise a question. For example, housing benefits may depend on the number of people living in the household. In this case we adjust the benefits according to the amount allowed for each child, even though this is not by virtue of their child status.

Figure 3 shows estimates of the average value of these components per child, expressed as a proportion of per capita disposable income. ${ }^{28}$ Countries are ranked by this normalised measure of net spending on children. The distinct roles of the transfer and tax systems are also shown. The operation of the tax system can reduce the gross effect of transfers if they are taxable. On the other hand, tax concessions can act like transfers, increasing the net allocation to children. Both features may be present in a national system and the net effect of including taxes can be negative, in which case the net effect is smaller than the effect of transfers alone, or positive, in which case the net effect is larger. Appendix 4 provides details of the contribution of each tax and transfer component to the net effect, by country.

\footnotetext{
${ }^{27}$ The information in Appendix 4 shows several countries where very small changes in parental benefits are included as child-contingent incomes. These correspond to cases where the parent is herself under the age of 18.

${ }^{28}$ Total national household disposable income divided by the national population. This is chosen as the measure of national income by which to normalise (rather than the commonly-used per-capita GDP) to avoid the artificial deflation of the scale of spending in Ireland and Luxembourg through the use of GDP..
} 
Figure 3

Spending on child contingent net transfers and tax concessions in EU15 in 2001:

per child spending as a proportion of per-capita household disposable income (\%)

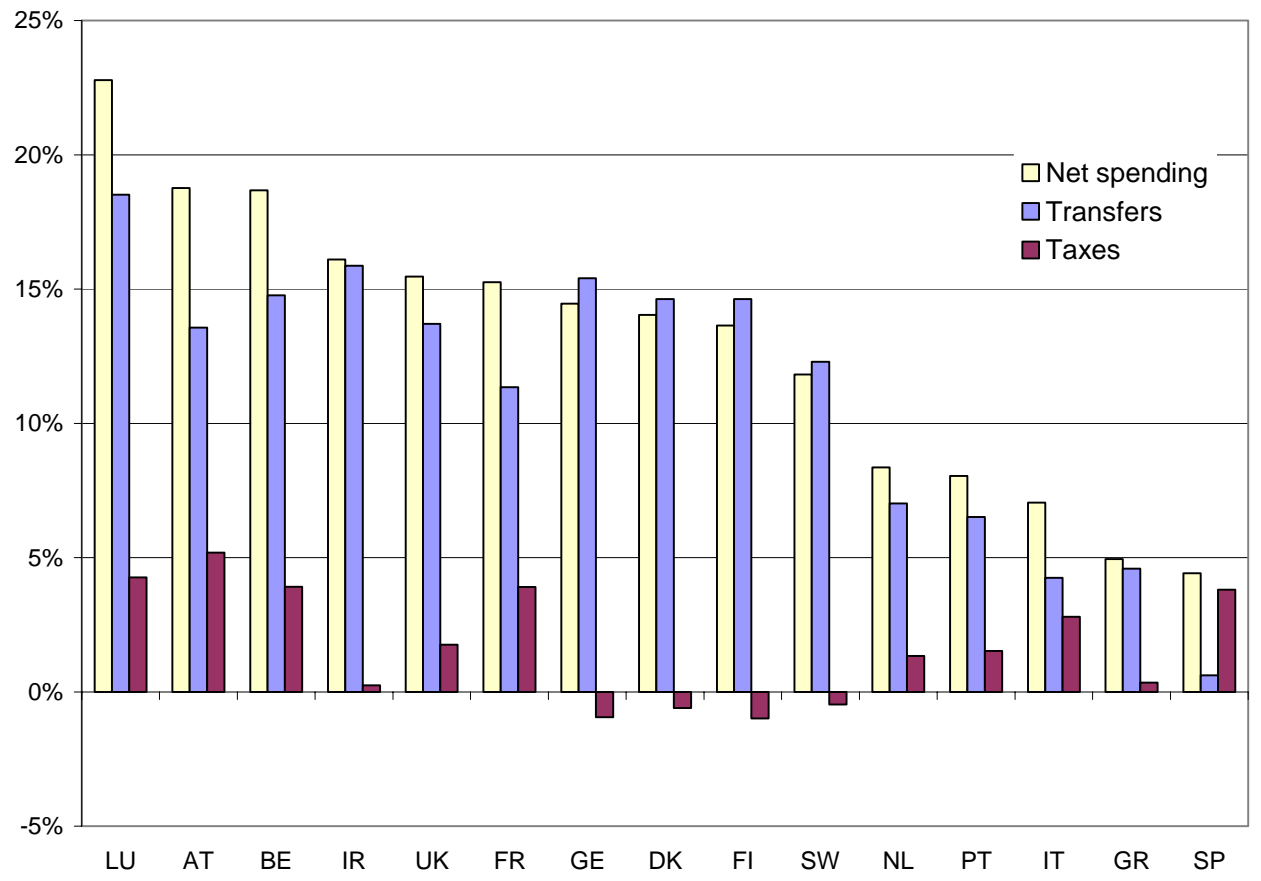

Source: Calculations by authors using EUROMOD version 28A.

Note: per capita household disposable income is calculated without equivalising: total income is added up over all households and divided by the number of people in the population.

Spending per child is highest in Luxembourg, where the net amount per child corresponds to $23 \%$ of per capita disposable income, followed by Austria and Belgium where it is about $18 \%$ of per capita disposable income. There is a large group of countries with very similar levels of net spending, around 15\% of income: Ireland, UK, France, Germany, Denmark and Finland. Sweden spends somewhat less and the five remaining countries spend much less (between 4\% and 8\%). Greece and Spain have the lowest spending of all, and Italy, Portugal, and the Netherlands have higher levels though significantly less than $10 \%$.

The importance of including tax concessions and the tax treatment of transfers in these comparisons stands out. Tax concessions are both of notable size (at least $2 \%$ of per capita income) and at least 15\% of the package for children in Luxembourg, Austria, Belgium, 
France, Italy and Spain. ${ }^{29}$ They also have a sizeable effect in the UK, the Netherlands and Portugal. Taxation of transfers reduces the net effect of the whole system in the Scandinavian countries and Germany. Both the tax and transfer effects are shown as net amounts. Within each, interactions between components are also captured. So, for example, where the tax effect is small this could be because the aggregate value of tax concessions and the tax collected on benefit incomes balance each other out. Similar interactions take place within the benefit calculations. So even where social assistance contains some child-contingent components, its aggregate value (shown in Appendix 4) may rise rather than fall when household incomes are re-calculated without children, due to the removal of child benefits from the income assessment. Without including these aspects of the redistributive systems the picture, and indeed the country ranking by level of aggregate spending, would look rather different.

Having established that the scale of net spending on children varies widely across countries, we now assess the extent to which the child-contingent incomes cover the extra needs of the household due to having children. Our approach is to compare equivalised income for households with children with those for exactly the same household, assuming there were no children, but all other things remaining the same. ${ }^{30}$

Comparing equivalised incomes with and without children involves making two distinct calculations. First, we take no account of children in the calculation of household needs. Effectively the equivalence scale becomes the square root of the number of adults. Then, we remove the income received by virtue of the presence of children. Although this

\footnotetext{
${ }^{29}$ In the Austrian case this may be partly due to our assignment of a child tax credit (Kinderabsetzbetrag) to taxes whereas it is paid in practice as a cash transfer.

${ }^{30}$ These calculations are conceptually similar to replacement rate calculations using microsimulation methods see Immervoll and O’Donoghue (2003). The approach is also similar to that taken in model family analysis where the reference income is calculated for an otherwise identical family without children. See Bradshaw and Finch (2002).
} 
does include small amounts of original income earned by children, its main components are the net transfers and tax concessions received because of the presence of children. Taking the children out of the needs assessment causes household equivalised income to rise. Deducting the components of income due to the presence of children causes equivalised income to fall.

The results of this exercise are highly dependent on the equivalence scale used, and in particular the implicit assumptions that: (1) child needs are proportional to household income (that is, the scale is equally applicable at all levels of income); and (2) that there are increasing economies of scale in the numbers of children (using the square root scale implies that each child in a large family needs less in absolute terms as well as a proportion of the whole than a child in a small family). However, this approach is still of value because our focus is comparative and the extent to which having children makes households (financially) worse off varies with the tax and transfer system.

The results are shown in Figures 4a and 4b. The rise in equivalised income when children are removed from the sharing of household resources is indicated in Figure 4a for each country by the contrast between the first two bars. In other words, the distance between these bars indicates the additional household needs due to the presence of children. The fall in equivalised income due to the loss of child-contingent support from the state is indicated by the contrast between the second and third bars. The fact that the third bar remains everywhere higher than the first indicates that in all countries child contingent incomes do not compensate for the extra needs of children as attributed by the equivalence scale. The distance between the second and third bars indicates the amount of this support. Figure $4 \mathrm{~b}$ represents this information in percentage terms, the fraction of the total increase in needs due to the presence of children accounted for by child-contingent transfer payments from the state. 
Figure 4a

Equivalised household income with and without children and child-contingent incomes in EU15 in 2001: all households with children (PPP-adjusted euro per year)

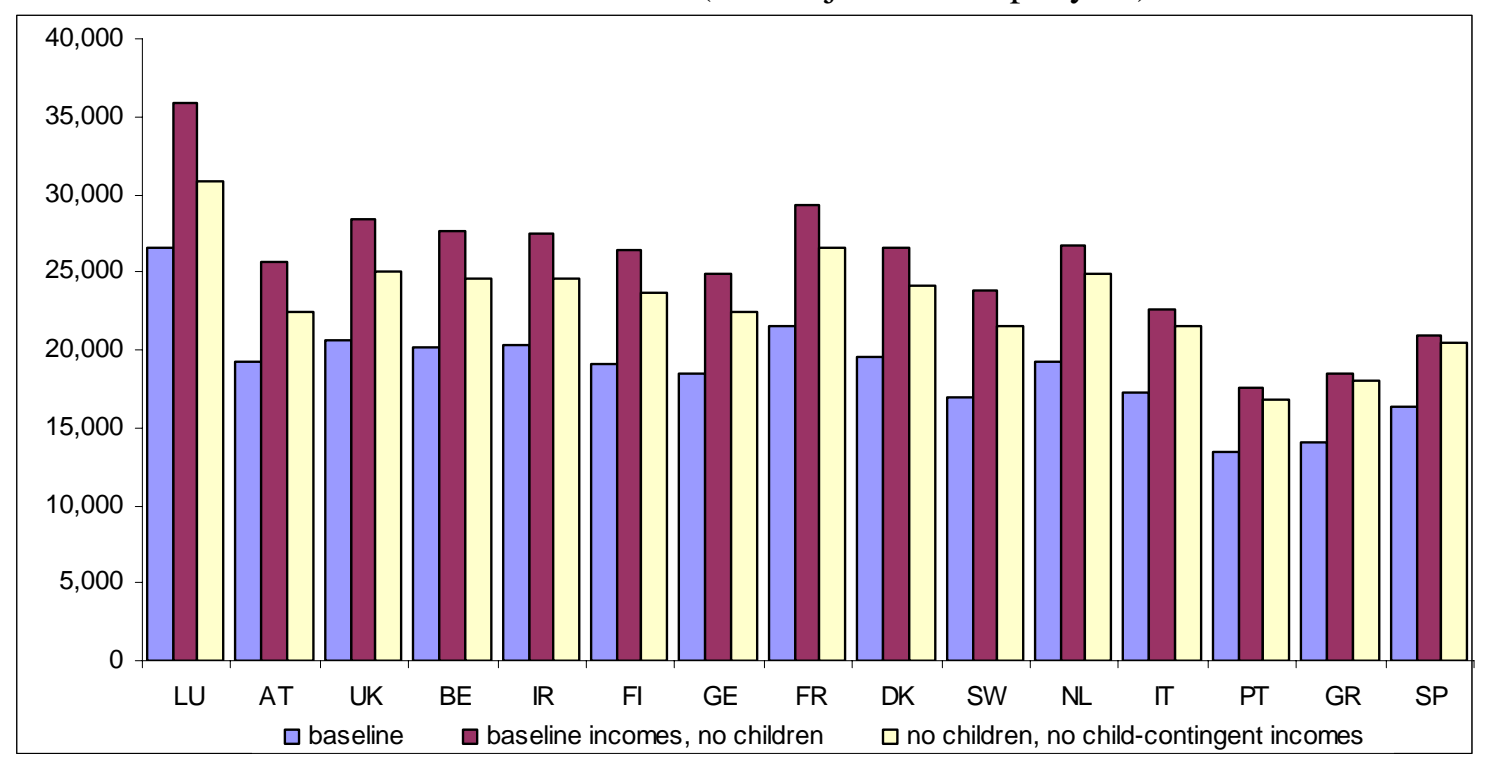

Figure 4b

Percent of income needs due to children covered by child-contingent state support in the EU15, 2001

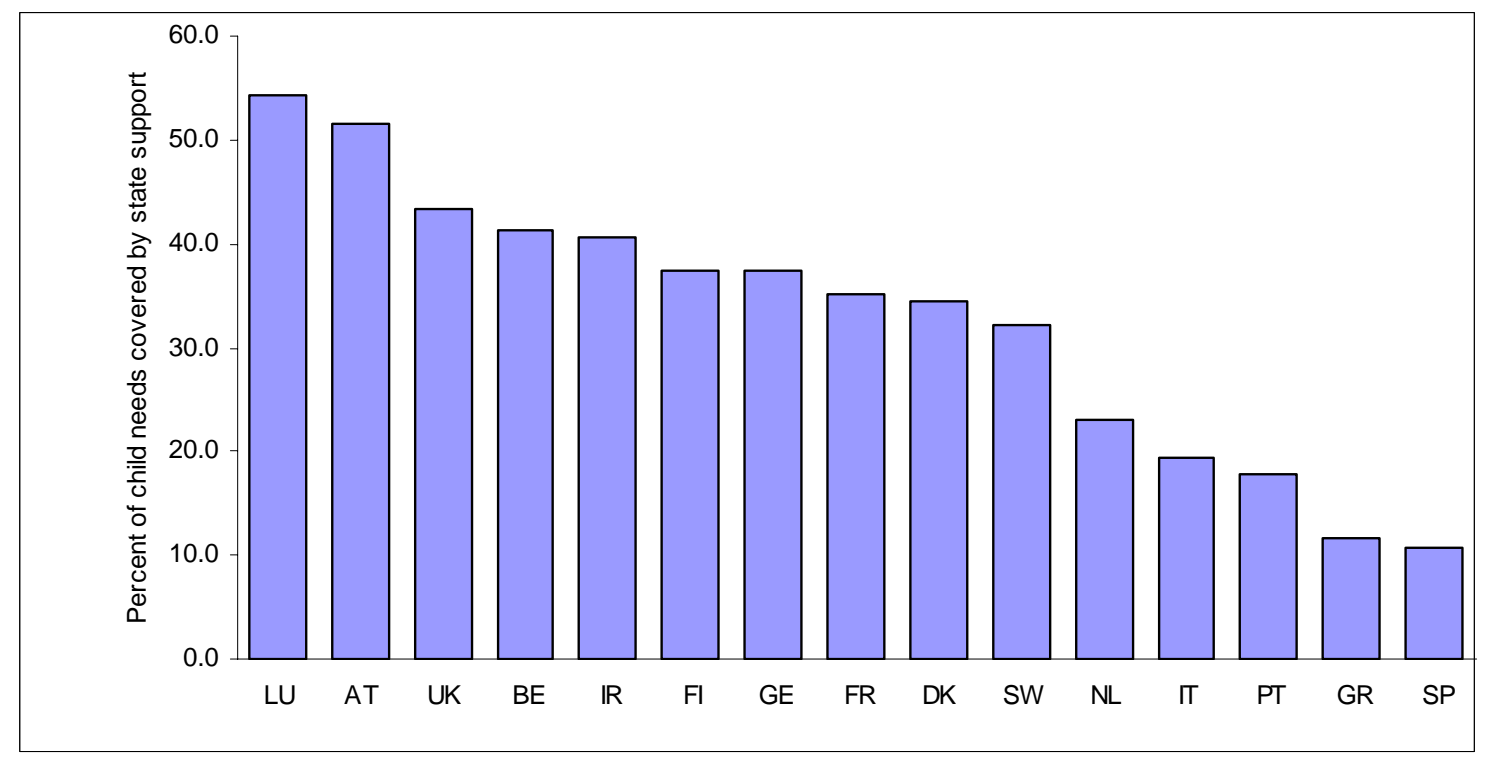

Source: Calculations by authors using EUROMOD version 28A.

The countries are ranked in Figure 4a by the share of this shortfall in state support in the overall "cost of children", showing that the extent to which the state bears the costs of 
children varies considerably (when measured in this way). This is explicitly depicted in Figure $4 \mathrm{~b}$, and ranges from as high as $54 \%$ in Luxembourg and $52 \%$ in Austria to as low as $12 \%$ in Greece and 11\% in Spain. All of the Southern countries offer the least in direct support for children with state compensation remaining below $20 \%$ of costs. The Netherlands is just above this at $23 \%$. State support is relatively high in UK (43\%), Ireland and Belgium (both 41\%). For the rest of the countries, including the Scandinavian countries, it amounts to about one third of the costs.

The extent to which these observations are dependent on the choice of equivalence scale can be judged by comparing Figure 4a with Figure A4a in appendix 3, which repeats the calculations using the modified OECD equivalence scale. A key difference is that each child receives the same weight using the OECD scale, whereas the square root scale applies a smaller additional weight the larger the family. ${ }^{31}$ Apart from one-child two-parent families and one- or two- child one-parent families, the weight given to each child (as a proportion of the total family weight) is higher using the modified OECD scale. On these grounds we would expect the appendix version of the figure to show a state compensation as a lower proportion of total costs. While the majority of households with children in all countries considered have either one or two children, the proportion with three or more varies from $4 \%$ in Germany to $18 \%$ in Ireland. So we might expect some differential effect across countries. In fact, the aggregate picture is very little altered by the different weights given to children by family size. Using the modified OECD scale reduces the estimate of the proportion of the costs of children which are compensated through child contingent parts of the tax and transfer system, but just by one or two percentage points in all countries.

\footnotetext{
${ }^{31}$ The modified OECD equivalence scale weights each household as 1 , adding 0.5 for each person additional to the first aged 14 or older and 0.3 for each person aged less than 14 .
} 
The ranking of countries and the general shape of Figure 4b is very similar to that shown in Figure 3: the proportion of the cost of children met by state spending is, not surprisingly, correlated with the aggregate size of child contingent spending. However, the ranking is not identical, reflecting cross-country differences in the incidence of spending according to the level of household income and, in some respects, household composition.

In Figure 5 we consider the incidence by income more directly. This examines the extent to which child contingent payments are targeted on children in poor households. The figure repeats the calculations underpinning Figure 3, just showing the net effects of transfers and taxes and comparing the effects for poor children with those of all children.

Figure 5

Spending on child contingent transfers and tax concessions in EU15 in 2001: per child spending on all children and poor children as a proportion of per-capita household disposable income (\%)

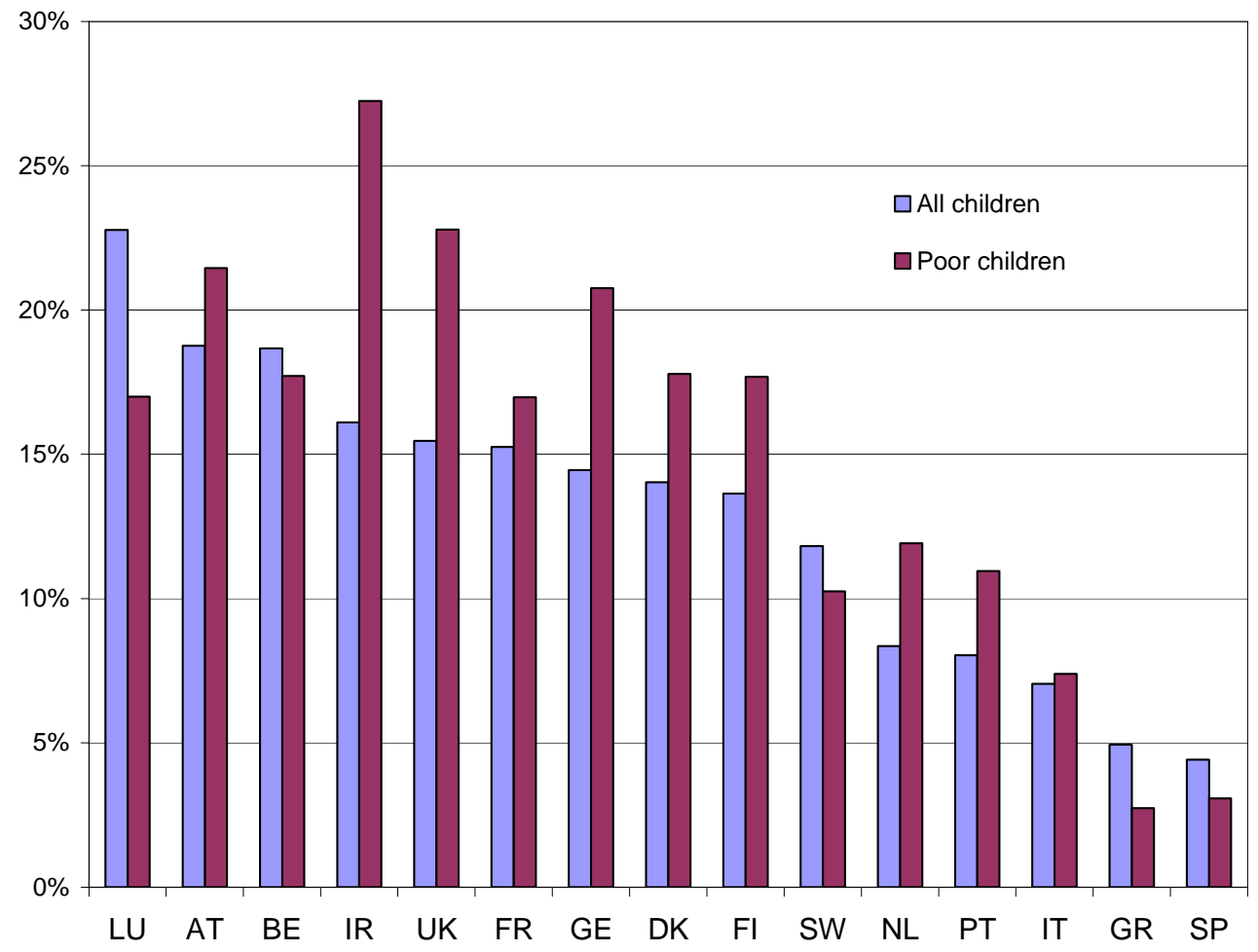

Source: Calculations by authors using EUROMOD version 28A.

In all but five countries spending per child is larger for poor children than on average. The exceptions are Luxembourg, Belgium, Sweden, Greece and Spain. Spending is particularly 
targeted on poor children in Ireland, where it is $70 \%$ higher than on children in general, and is also 50\% higher in UK, Germany and the Netherlands. Two of the exceptions, Greece and Spain, spend very little directly on tax-benefit components for children, and even less on poor children. This is a reflection of these countries' reliance on tax concessions which rarely benefit the poor. In Belgium, Luxembourg, and Sweden spending is slightly lower on poor children than on children in general. In the case of Belgium and Luxembourg this reflects the fact that the main sources of child-contingent incomes are universal benefits and tax allowances rather than transfers targeted on low income households (see Appendix 4 for details).

5. Alternative measures of public resources for children and the impact on child poverty We summarize our major results by focusing on four of the alternative measures of public resources directed to children presented in the previous sections: (1) net child contingent payments including tax concessions, derived using EUROMOD simulations and presented in Figure 3; (2) child contingent transfers alone, without the positive or negative effects of taxes, also derived using EUROMOD and shown in Figure 3; (3) the total cash payments made in the form of family benefits using information in the OECD Social Expenditure Database and presented in Table 1; and (4) the comprehensive measure of total household transfer payments, calculated for those under 18 years of age as the proportion of household disposable income, using the EUROMOD database and shown for all age groups in Figure 2. We have argued that the implications of the tax system need to be recognized, suggesting that method (1) may offer a more accurate measure of child targeted resources than (2) and (3). We have also argued that transfers not specifically labelled for families may be important, as may interactions between transfers, suggesting that methods (1) and (2) may be preferred over (3). Our discussion has also argued that in some sense all three of these measures may be too 
narrow as indicators of public resources benefiting children in that government spending on other cash programs also has implications for them. Measure (4) offers at the broadest recognition of these facts, but should not be understood as reflecting solely the consequence of budgetary decisions, as these interact with household structure and labour market behaviour. $^{32}$

In what follows we highlight two issues. First, we ask whether calculations of the net effect of child-contingent spending (those taking into account interactions, and including tax concessions and child-contingent components of other transfers) provide an appreciably different picture than that produced using data solely on government expenditures. Secondly, there is the question of whether the source of the spending — or the target group for a particular benefit-matters. How relevant is, for example, the pension income received by a co-resident grandparent or the unemployment benefit received by a parent to an assessment of government support for children? In other words, would it be misleading to focus on just the child benefit received on behalf of the child?

Figure 6 compares the relative size of spending on children using the four alternative measures. In each case the country specific estimate is measured as a ratio to the unweighted average over the 15 countries, so that the relative position of countries using each measure can be compared. ${ }^{33}$ Countries are ranked by spending according to measure (1)—child contingent net transfers and tax concessions_-and the rankings using the other measures are shown in the table below the chart (the country with the highest value of spending on children being ranked first).

\footnotetext{
32 The same applies, but to a lesser degree, to the other three measures.

${ }^{33}$ Each of the four methods of assessing the level of spending uses its own normalization across countries, to account for differences in size and/or income level. In the first and second measures, per capita disposable income is used, in the third, GDP and in the fourth household disposable income. Differences in the relative size of these income measures across countries will affect the comparisons made here.
} 
It is clear that the different measures do have an effect on the country rankings and the distance between the country estimates. Some of the changes in rankings are very significant. For example, using the household transfer measure (4) Sweden counts as the highest spender; using child contingent incomes (1) it counts as the $10^{\text {th }}$ from top. The approach to measuring resources for children matters. At the same time, there are two clear groups between which no re-ranking occurs. The four Southern countries, together with the Netherlands make up the low spending group, and the remaining ten countries are a group within which at least one of the measures ranks each country in the top three. An exception is France, which remains in the middle on all measures.

Secondly, as discussed in the previous section, the inclusion of the tax system in the accounting of spending on children (measure (1) compared with measure (2)) has a significant effect on the position of some countries. In the low spending group it greatly increases the estimate of the amount Spain and Italy transfer to children and in the high spending group the same is true for Austria, France and Belgium. On the other hand, allowing for the taxation of transfers in Ireland, Germany and the three Scandinavian countries reduces the effect of transfers themselves. 
Figure 6

Government resources for children in the EU15 using four different measures, 2001

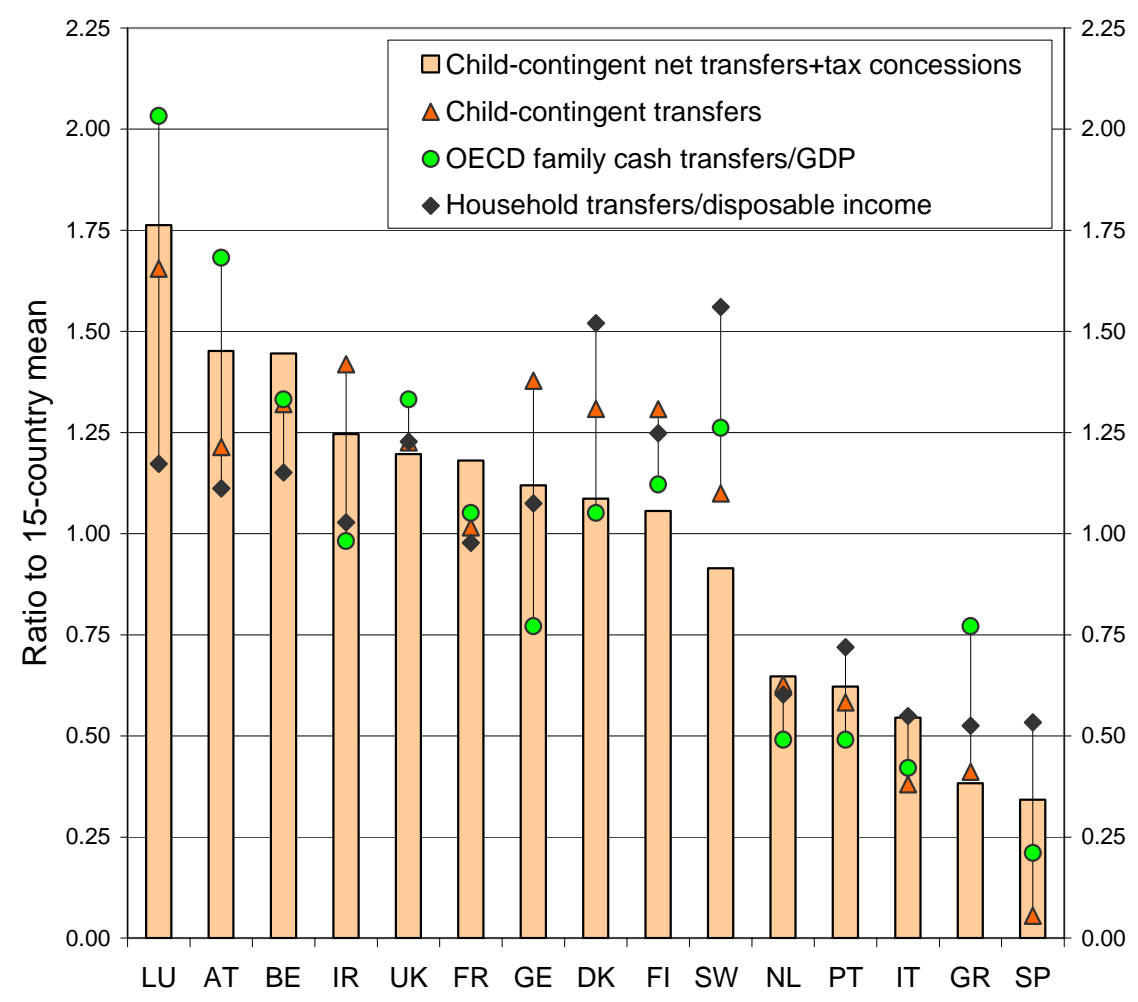

\begin{tabular}{l|rrrrr|rrrrr|rrrrr}
\hline Country Rankings & LU & AT & BE & IR & UK & FR & GE & DK & FI & SW & NL & PT & IT & GR & SP \\
\hline (1) Child contingent transfers+tax & 1 & 2 & 3 & 4 & 5 & 6 & 7 & 8 & 9 & 10 & 11 & 12 & 13 & 14 & 15 \\
(2) Child-contingent transfers & 1 & 8 & 4 & 2 & 7 & 10 & 3 & 5 & 6 & 9 & 11 & 12 & 14 & 13 & 15 \\
(3) OECD family cash transfers & 1 & 2 & 4 & 9 & 3 & 8 & 10 & 7 & 6 & 5 & 13 & 12 & 14 & 11 & 15 \\
(4) Household transfers & 5 & 7 & 6 & 9 & 4 & 10 & 8 & 2 & 3 & 1 & 12 & 11 & 13 & 15 & 14 \\
& & & & & & & & & & & & & & &
\end{tabular}

Source: See Table 1 and Figures 2 and 3

Only allowing for family benefits, as in measure (3), inflates the relative size of spending in countries where some of these benefits are taxed back, but it also reduces the estimate compared with (1) if there are transfers that are child-contingent but not categorised as family benefits. Countries where the second factor outweighs the former include Belgium, France, Ireland, Germany and to a lesser extent the Netherlands, Portugal and Italy. 
Finally, including all cash transfers but no tax effects and assuming that children benefit equally from all sources of household transfers significantly increases the estimates of relative spending in the three Scandinavian countries and Spain, and also in Portugal and Greece. This is to be expected in the Southern countries where child-specific spending is low on any grounds, where pensions make up large proportions of social spending and where the likelihood of children sharing households with their grandparents is relatively high. In the Scandinavian countries the key factor is, as noted earlier, that much of the support for families is routed through labour market support, not child-contingent payments.

What difference do these measurement issues have for the impact of public resources on child poverty rates? What elements of government budgets play the most important role in reducing child poverty rates: child-contingent transfers, tax concessions, broader transfers directed to other groups but mediated through families and labour markets to be directed to children? To what extent does accounting for the interaction between different parts of the system (e.g. through the taxation of benefits) make a difference to cross-country comparisons?

Figure 7 compares the impact of transfers and taxes on child poverty using EUROMOD estimates of child poverty with household disposable income as the "baseline", and compared with: (1) household income without net child-contingent spending; (2) household income without all transfers; and (3) household income without all transfers and before taxes. In each case the poverty threshold is the same.

The countries are ranked according to the child poverty rate after all taxes and transfers, the lightly shaded bar. The child poverty rate without child-contingent transfers and tax concessions is indicated by the height of the darkly shaded bar. Child poverty would be much higher in the absence of child contingent transfers in most countries. The effect in absolute terms is most dramatic for the UK and is also substantial in Luxembourg and France. 
For example, without child contingent transfers and tax concessions the UK child poverty rate would be just over $30 \%$, rather than around $12 \%$. On a proportional basis the reduction in child poverty rates is smallest in Spain and Greece and largest in Sweden, Denmark, Finland, Austria and Luxembourg. In Ireland, Italy and Portugal the reduction is around a third while in Germany, UK, France and Belgium it is between 60\% and two-thirds. In the Netherlands it is less than half. Sweden and Luxembourg are in the group of countries with the highest proportional reduction in child poverty due to child-contingent transfers and tax concessions, and Belgium is in the middle group. This is in spite of the fact that spending on poor children is lower than on average in these three countries, and is consistent with their budgetary systems being particularly effective at keeping children out of poverty.

At the same time the information in the figure also shows that child poverty rates are strongly affected by public resources not specifically addressed to children. This effect is also larger in some countries than others, as illustrated by the contrast between the darkly shaded bars and the height of the circle-topped lines. As might be expected, the contrast is largest (relative to that of child-contingent spending) in the Scandinavian countries, because of public support to working parents. The pre-tax, pre-transfer child poverty rate in Sweden, for example, is not much different than in the UK. And while both countries offer considerable child-contingent support the difference in final outcomes is in large measure due to nonchild-contingent public transfers. The impact of this part of the transfer system is also important in the Southern countries, but in this case because of the relatively more important role of intra-household transfers from other co-resident adults.

The reduction in poverty rate due to all transfers is the measure often used to assess the effect of government policies on poverty, as for example in Dennis and Guio (2004). However, it does not always take account of the tax or contribution systems, either through the provision of concessions or, more importantly for the poor, in relation to tax and 
contributions paid on the transfers that are received. Taking away the transfers without giving back the taxes paid on them will over-estimate the impact of the transfer system on poverty reduction. Assessment of the net effect of the transfer system is not possible without the microsimulation tools of the type used here. It is instructive, nevertheless, to compare the "before transfers" child poverty rates with those that would apply before both transfers and taxes. Adding taxes back to incomes (as indicated by the black triangles) reduces child poverty rates in all countries, relative to the rates using incomes without all gross transfers. The reduction is very significant in some countries. ${ }^{34}$ Of course some of the taxes that have been added back in correspond to taxes and contributions on original income. The point, in this context, is to demonstrate the relevance of taxes.

Figure 7

The child poverty rate in EU15 in 2001, with and without child-contingent incomes, all transfers, and all transfers and taxes

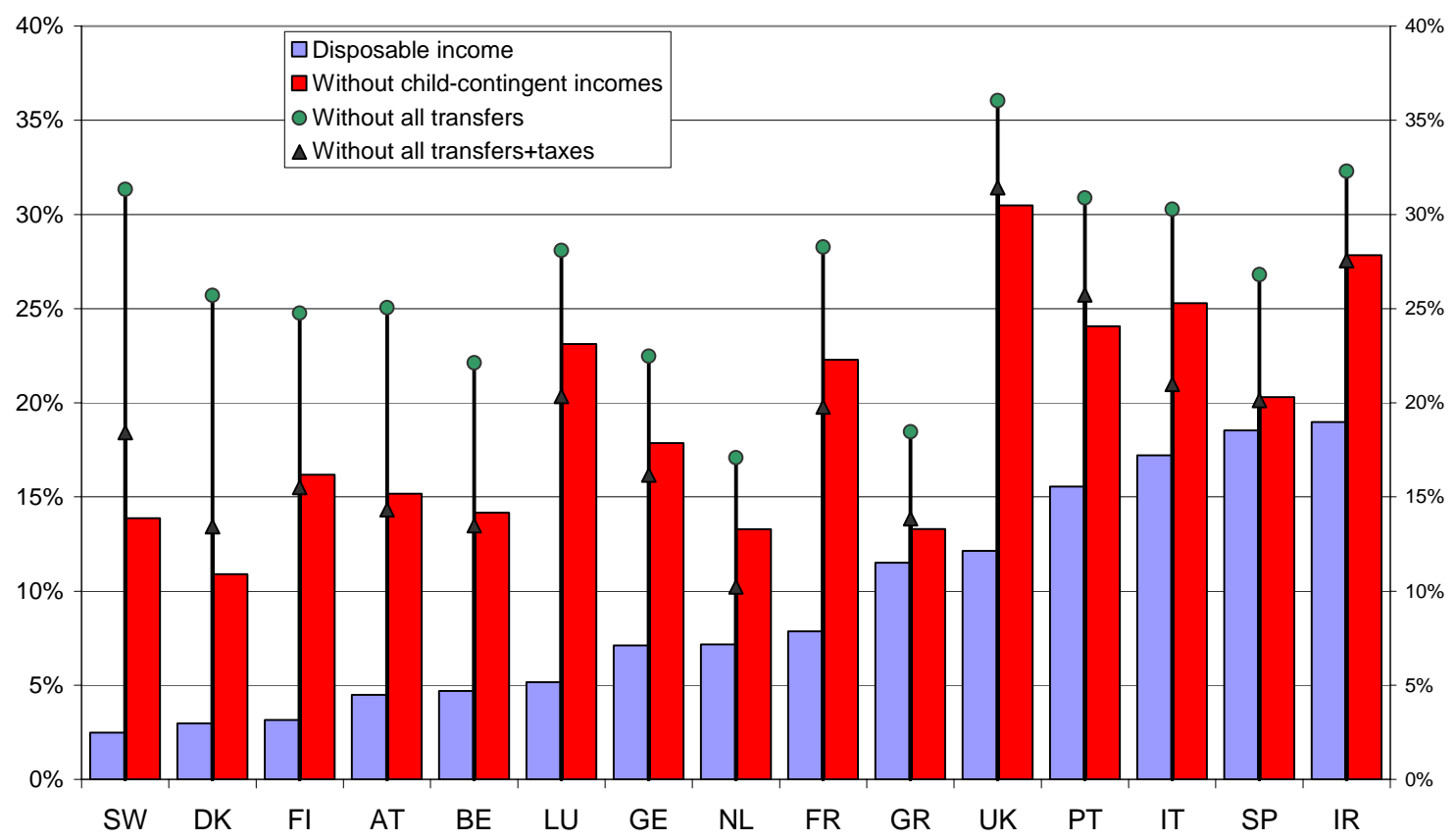

Source: Calculations by authors using EUROMOD version 28A.

\footnotetext{
${ }^{34}$ The numbers behind Figure 7 are given in Table A3.3, along with corresponding estimates using $60 \%$ of the median as the poverty line and the modified OECD equivalence scale.
} 
We would expect the countries spending a lot on children that nevertheless remain below the poverty line-Ireland, UK, Germany and the Netherlands (see Figure 5) — to be more effective at reducing measures of poverty severity. That is to say, the priority may be on the poorest of the poor. To examine this we focus on the net effect of child contingent components of the transfer and tax systems on a measure that takes account of the depth of poverty. This is illustrated in Figure 8. Rather than the headcount ratio the Foster, Greer and Thorbecke (1984) index, with an aversion parameter a=1, is used (FGT1). ${ }^{35}$ Countries are ranked by this index of child poverty "severity”, with child-contingent incomes included in income.

First, compared with Figure 7, it is clear that there is a much greater range in poverty severity across countries than poverty rate. The ranking of countries is not the same, although the tendency persists for the Scandinavian and continental countries to have the lowest rates, and for the Southern countries and Ireland and the UK to have among the highest. Second, in all countries child-contingent transfers and tax concessions have bigger proportional impact on poverty severity than on the poverty rate. The greatest absolute impact is in UK and Ireland (reflecting their use of means-tested benefits that do not necessarily guarantee incomes above the poverty line we use). The greatest proportional impact is in Luxembourg, Finland and France as well as the UK. Again, Luxembourg child contingent incomes succeed in reducing child poverty severity to the second lowest level from the $8^{\text {th }}$ highest.

\footnotetext{
${ }^{35}$ The FGT1 is the sum over poor children of the proportional shortfall of income below the poverty line, averaged across all children.
} 
Figure 8

Child poverty severity (FGT1) in EU15 in 2001, with and without child-contingent incomes

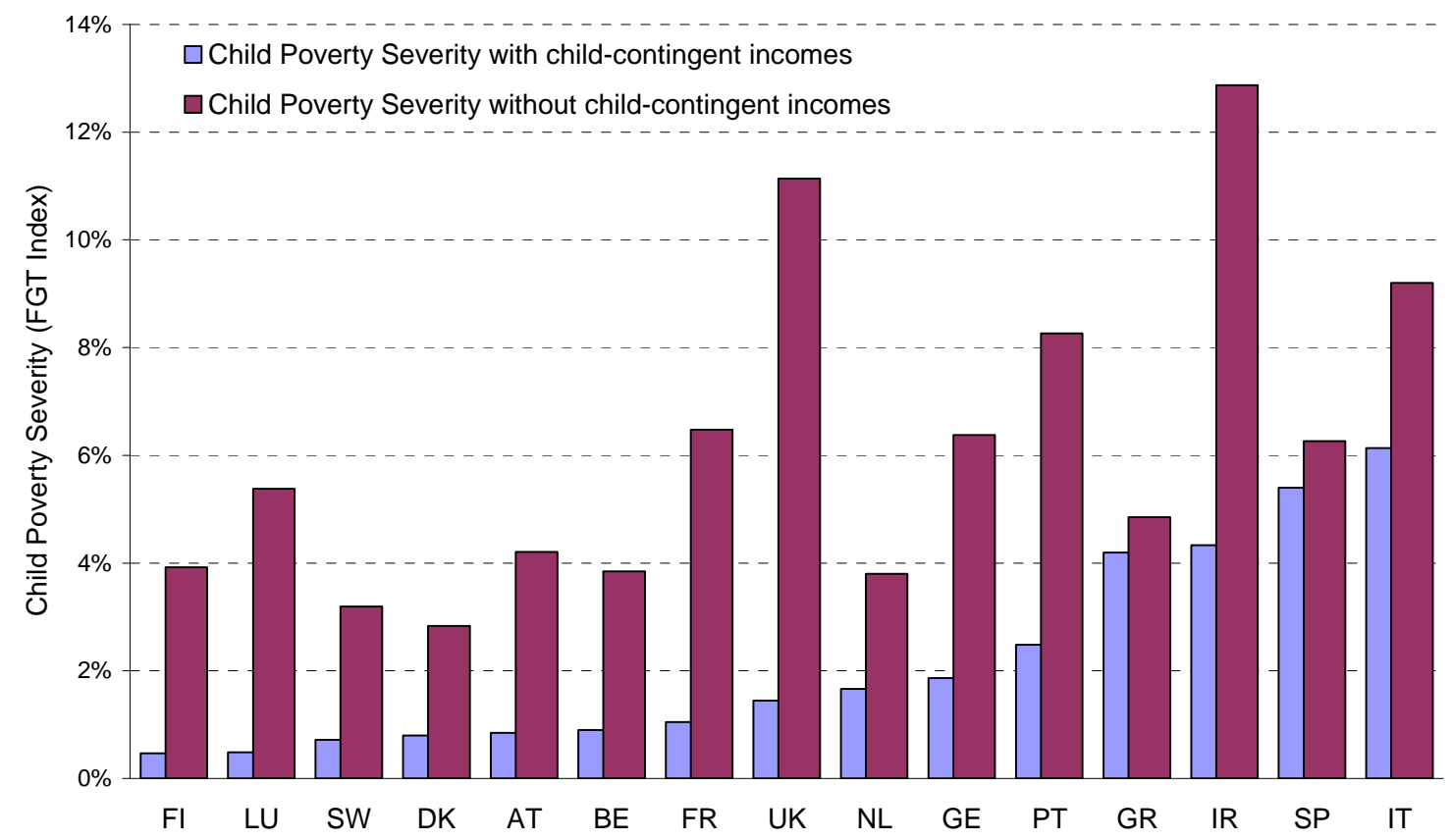

Source: Calculations by authors using EUROMOD version 28A.

The relationship between child contingent incomes and child poverty is depicted in

Figures 9a and 9b, the former showing the percentage point reduction in child poverty rates and the latter the proportional reduction in poverty severity. There are clear positive relationships between scale of spending and poverty reduction. On average across all 15 countries for every percentage point increase in child contingent resources the headcount ratio falls by 0.75 percentage points and the severity index by $4.9 \%$. This does not of course mean that the relationship is the same in each country (Atkinson 2005). Indeed, the fact that there is a scatter of points around the line depicting this average tendency shows that some countries are more effective than others at reducing child poverty for a given level of spending. Tax and transfer systems have many goals, poverty reduction being just one among them. The tax and transfer systems of the UK, Finland, France, Portugal and Sweden (appearing above the line in both charts) are relatively cost effective at reducing child poverty in those countries. Spain, Greece, Ireland, Belgium and Austria (below the line on both 
charts) have tax and transfer systems that are relatively ineffective in this respect, given the overall cost of the systems. These two groups of countries each represent quite a cross-section of welfare state types and levels of spending.

At the same time, reductions in child poverty—particularly absolute reductions in the rate as shown in Figure 9a-are difficult to achieve if poverty rates are already low. Some of these high spending countries may be as concerned about children a little above the poverty line as those below it, as demonstrated by their use of universal benefits and tax concessions benefiting the better-off. More generally, there may be indirect associations between levels of spending on children and the amount of child poverty. Figure 10 makes explicit the inverse relationship between the child poverty rate and the level of child-contingent spending. In this case, the countries that appear to have lower poverty rates than predicted by their level of spending (those below the line) include Greece, Belgium and Austria. These three countries are among the five that appeared to be achieving less child poverty reduction than they might through their child contingent transfers and tax concessions (Figures 9a and 9b). 
Figure 9a

Level of spending on child-contingent incomes and child poverty rate reduction

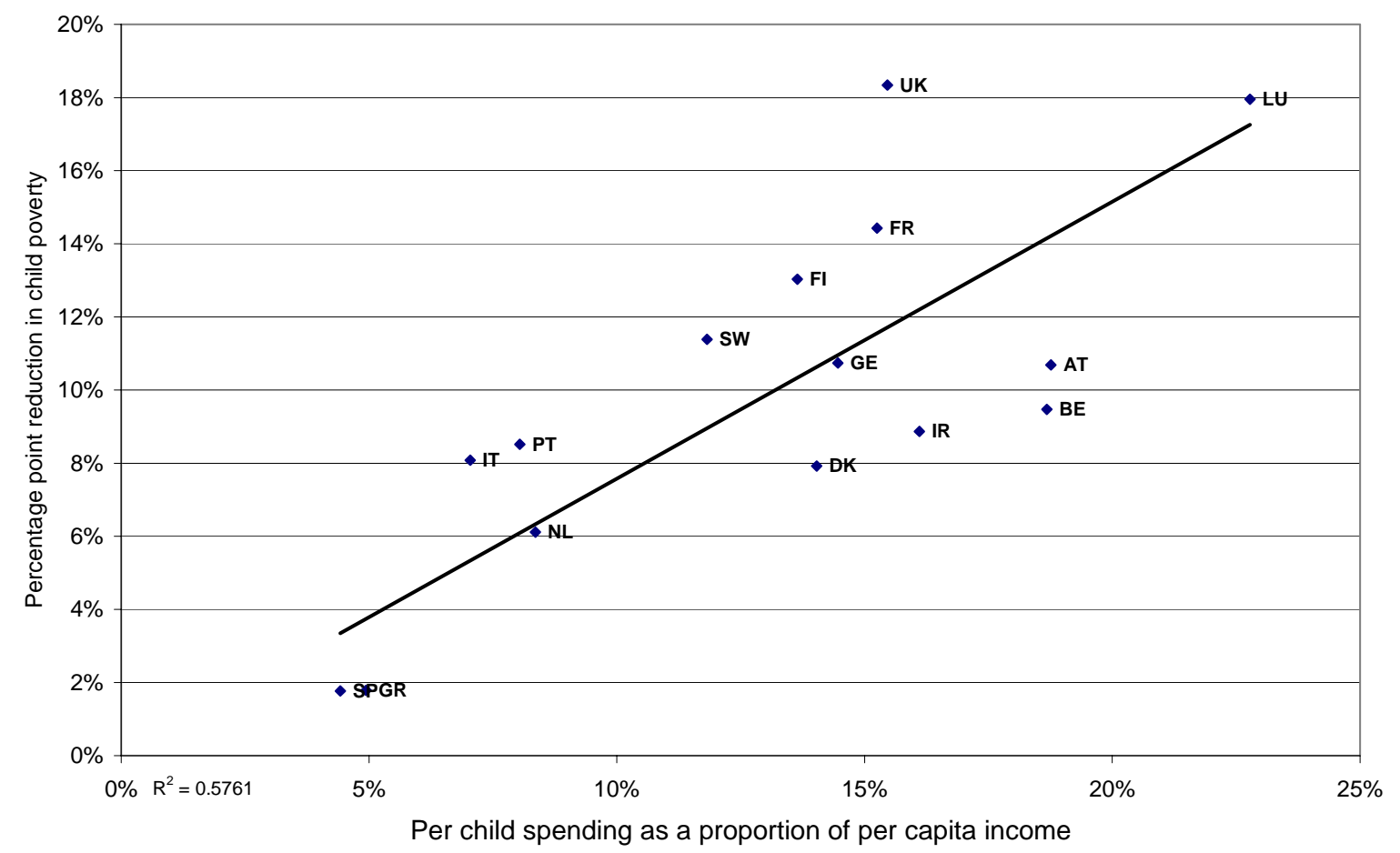

Source: Calculations by authors using EUROMOD version 28A.

Figure 9b

Level of spending on child-contingent incomes and reduction in child poverty severity

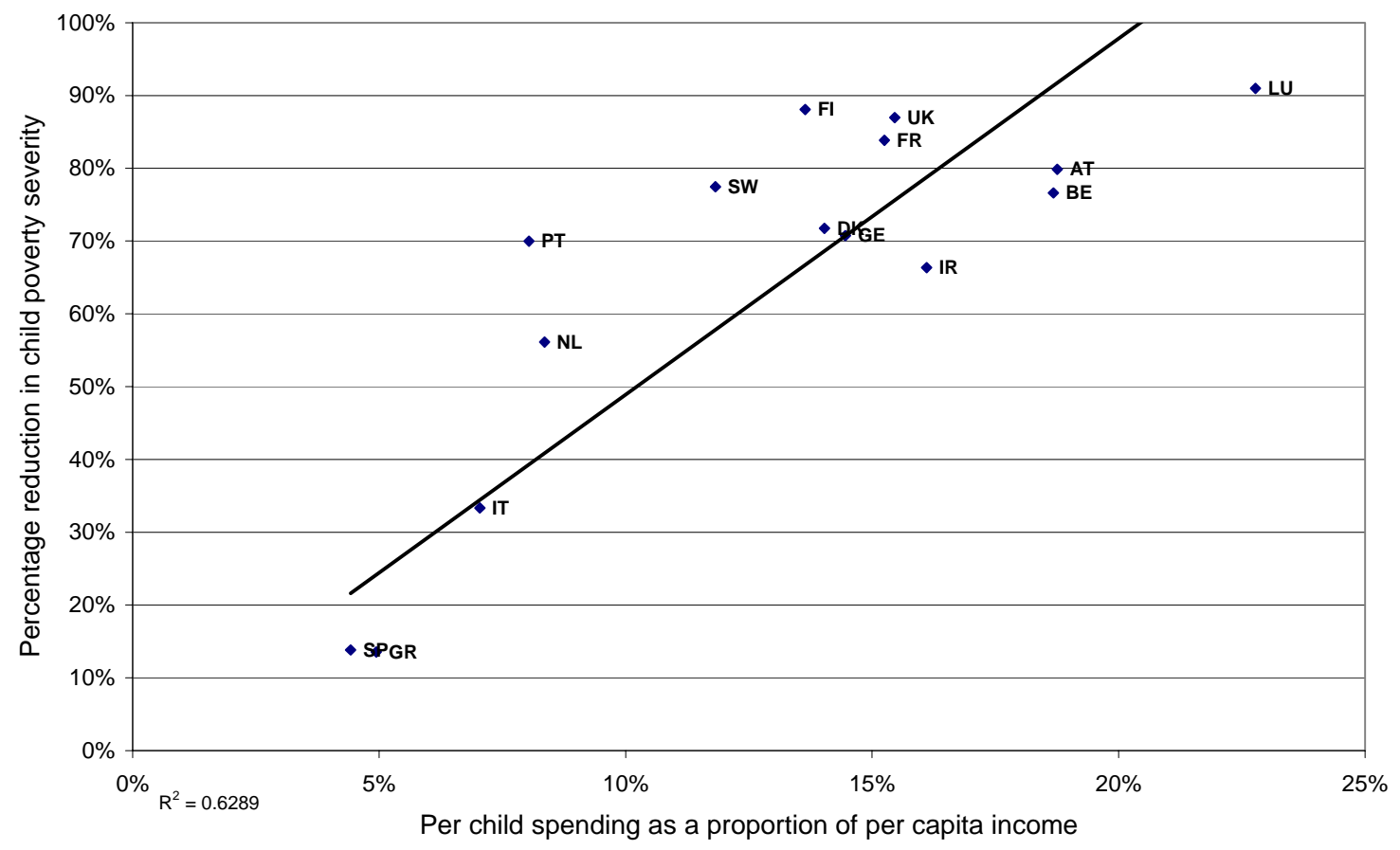

Source: Calculations by authors using EUROMOD version 28A. 
Figure 10

Level of spending on child-contingent incomes and the child poverty rate

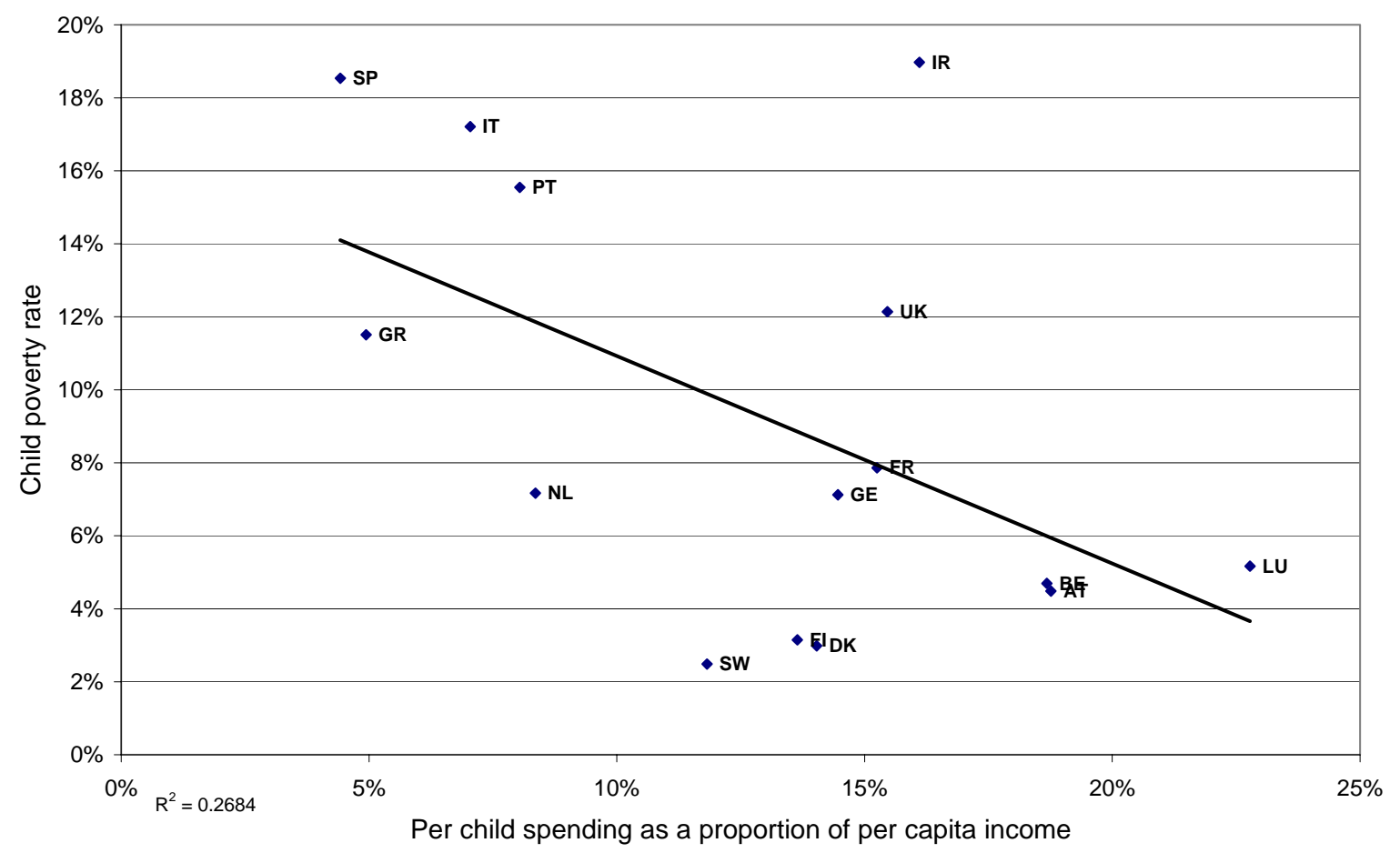

Source: Calculations by authors using EUROMOD version 28A.

In the case of Greece spending is low and pre- child contingent income poverty is also relatively low. This is a prime example of a Southern European country which relies on the family for most of the financial support for children (Matsaganis et al., 2004). Austria and Belgium achieve poverty rates lower than predicted by the level of child-contingent spending through a mixture of relatively low poverty risk before this spending together with spending that is effective at reducing child poverty but which is at the same time part of a strategy to support children more generally, and hence appears expensive in terms of its child poverty reduction. This also applies to other countries, which are "above the line" in either or both of Figures 9a and 9b: Finland, Sweden Denmark, the Netherlands, Luxembourg and France. With the exception of Greece, the Southern European countries are low spending but have higher than predicted poverty rates. In Portugal and Italy the child-contingent systems are quite cost effective in terms of poverty rate reduction but the Spanish system is not. Spending 
in the UK and Ireland is at a similar level but the UK achieves more in terms of reducing the rate and, particularly, the severity of child poverty. However, the UK still has a higher than predicted rate. Together with the effectiveness of the severity reduction this suggests that the amount spent per child is not sufficient. In Ireland this also appears to be the case, but the high pre-child-contingent income child poverty rate and intensity in Ireland seems less amenable to reduction through the Irish tax-benefit system for children than is the case in the UK.

\section{Conclusion}

We use a static microsimulation model, EUROMOD, to compare a number of different measures of the public resources directed to children across the EU 15 countries. Our analysis can be summarized under three broad headings, which relate to the three questions posed in the introduction. The first concerns the age incidence of government taxes and transfers, and refers to the priorities embedded in government budgets. We find that in most countries children receive a higher proportion of their share of household income from government transfers than young and middle-aged adults, but this is not universally the case as Italy, Spain and Greece are important counterexamples. Low income children receive 60 to $80 \%$ of their income from transfers in all countries with child poverty rates lower than $10 \%$. But the proportion is much lower, 20 to $30 \%$, in countries with higher child poverty rates such as Greece, Portugal, Italy and Spain. The UK and Ireland also have relatively high child poverty rates, but are exceptional in the degree of targeting of transfers on low income children. Further, in many high child poverty countries the low income population in their 50s receive a higher proportion of household disposable income from state transfers than those younger than 18 .

As stressed we recognize that these patterns are based on the broadest possible measure of public resources for children, one that is influenced not only by government budgets but also 
relies on the assumption that all sources of income in the household are shared with children. As such the number of co-resident adults, transfer payments directed to them, and their labour market behaviour play a role. For this reason we also examine only those payments from the state that depend on the presence of children. We use the unique powers of EUROMOD to calculate the net effect of child-contingent transfers and tax concessions and find that the value of these per child ranges from less than five percent of per capita household income in Greece and Spain to 23\% in Luxembourg. In all but five countries child contingent spending is higher for low income children than for the average child. We also find that tax concessions are an important component in many countries and cannot be ignored in making comparisons of the extent of public resources for children.

On this basis we attempt to address a second question about the extent to which the financial burden associated with children is met by the state. We offer a set of calculations that suggest that there is considerable cross-country variation in the fraction of the additional household needs arising from having children which is supported through government transfers. It is higher than $30 \%$ in 10 out of the 15 countries we study. It is as high as $50 \%$ in Luxembourg and Austria, but in the neighbourhood of $20 \%$ in the Netherlands, Italy, Portugal, and close to only $10 \%$ in Greece and Spain.

Comparing these with other measures of state spending on financial support for children we find that two groups of countries within EU 15 can be identified. The four Southern countries, Italy, Spain, Greece and Portugal together with the Netherlands make up one group, with relatively low levels of spending on children using every measure considered. The remaining ten countries make up the other group, with higher relative levels of spending on every measure. Within this higher spending group the relative ranking varies according to the approach taken: the extent to which it is focused on child contingent resources only or acknowledges that other programs also impact on children through the sharing of household 
resources; and the extent to which the positive and negative effects of the tax system are recognized. Luxembourg Austria and Belgium spend the most per child on the basis of net child-contingent spending and Sweden, Denmark and Finland spend most as a proportion of income if all transfers are considered, before tax.

Our third set of findings has to do with the relationship between various measures of public resources we calculate and child poverty. We find that poverty rates would be much higher in all countries if there were no child contingent transfers being made. But countries with the lowest poverty rates are those in which children benefit a good deal from other transfers not necessarily directed to them. In the Scandinavian countries this is because of public support to working mothers and fathers. The impact of the broader tax-transfer system is also important in the Southern countries because of the relatively more important role of intra-household transfers from co-resident adults.

In another set of countries with low poverty rates child contingent payments make a large contribution to child poverty reduction. These include Luxembourg, Belgium and Austria which are the three countries with highest per child spending and, after the Scandinavian countries the next lowest child poverty rates. These countries mainly make use of universal benefits and tax concessions. Their systems are not particularly targeted on low income children and indeed, in the first two of these countries more is spent per child on non-poor children than on the poor. Nevertheless the systems perform well in protecting children from poverty. In contrast, the two countries which target most by income, UK and Ireland, are the next highest spenders on a child-contingent basis (4th and 5th) but these countries rank lower in terms of child poverty rate $\left(10^{\text {th }}\right.$ and $\left.15^{\text {th }}\right)$. The form and structure of the system as well as the level of spending is clearly an important factor and an important avenue for future research. 


\section{References}

Adema W., 1999, Net Social Expenditure, Labour Market and Social Policy Occasional Papers, No.39, OECD, Paris.

Atkinson A.B., 1998, Poverty in Europe. Oxford: Blackwell publishers.

Atkinson A.B., 2005, "EUROMOD and the development of EU social policy”, EUROMOD Working Paper No. EM1/05, Microsimulation Unit, Department of Applied Economics, University of Cambridge.

Atkinson A.B., B. Cantillon, E. Marlier and B. Nolan, 2002, Social Indicators: The EU and Social Inclusion, Oxford University Press, Oxford.

Auerbach A J., L. J. Kotlikoff and W.Leibfritz, editors, 1999, Generational Accounting Around the World. Chicago: The University of Chicago Press.

Bradshaw, J. and Mayhew, E. (2003) "Are welfare states financing their growing elderly populations at the expense of their children?” Family Matters. Vol. 66 Spring/Summer, pp. 20-26.

Bradshaw J. and N. Finch, 2002, A comparison of Child Benefit packages in 22 countries, Department for Work and Pensions Research Report No. 174, London: CDS.

Callan T. and H. Sutherland, 1997, "The Impact of Comparable Policies in European Countries: Microsimulation Approaches”, European Economic Review, 41: 3-5, 627-633.

Chen W-H. and M. Corak, 2005. "Child poverty and changes in child poverty." UNICEF Innocenti Research paper No. 2005-02.

Dennis I. and A-C. Guio, 2003, "Poverty and social exclusion in the EU after Laeken- part 1", Statistics in Focus Theme 3 8/2003, Eurostat.

Dennis I. and A-C. Guio, 2004, "Poverty and social exclusion in the EU”, Statistics in Focus Theme 3 16/2004, Eurostat.

Duflo E., 2000, “Child Health and Household Resources in South Africa: Evidence from the Old Age Pension Program.” American Economic Review. Vol. 90, 393-98.

Expert Group on Household Income Statistics, The Canberra Group, 2001, Final Report and Recommendations. Ottawa: The Canberra Group.

Ermisch J., 1989, "Intergenerational transfers in industrialized countries: Effects of age distribution and economic institutions.” Journal of Population Economics. Vol. 1, pp. 269-84.

European Commission, 2001, Indicators Sub-Group: Report from the Chairman, Social Protection Committee, Brussels. 
Foster J.E., J. Greer and E. Thorbecke, 1984, “A class of decomposable poverty measures”, Econometrica 52, pp. 761-766.

Hancock R., S. Pudney, G. Barker, M. Hernandez and H. Sutherland, 2004, “The Take-Up of Multiple Means-Tested Benefits by British Pensioners: Evidence from the Family Resources Surveys”, Fiscal Studies, 25 (3), 279-303.

Heady C., T. Mitrakos and P. Tsakloglou, 2001, “The distributional impact of social transfers in the EU: Evidence from the ECHP”, Fiscal Studies 22, pp. 547-565.

Hicks C., 1998, “The Age Distribution of the Tax/Transfer System in Canada.” In M. Corak (editor), Government Finances and Generational Equity. Ottawa: Statistics Canada.

Hodgkin R. and P. Newell, 2002, Implementation Handbook for the Convention on the Rights of the Child, Fully revised edition. New York: United Nations Children’s Fund.

Immervoll H. and C. O’Donoghue, 2003, “Employment Transitions in 13 European Countries. Levels, Distributions and Determining Factors of Net Replacement Rates”, EUROMOD Working Paper EM3/03, Microsimulation Unit, Department of Applied Economics, University of Cambridge.

Immervoll H., C. O’Donoghue and H. Sutherland, 1999, “An Introduction to EUROMOD”, EUROMOD Working Paper EM0/99, Microsimulation Unit, Department of Applied Economics, University of Cambridge.

Kelly J. and M. Everett, 2004, “To borrow and prosper: financing the Celtic Tiger”, paper presented at the $28^{\text {th }}$ General Conference of the International Association of Research in Income and Wealth, Cork, $21^{\text {st }}-28^{\text {th }}$ August. www.iariw.org/papers/2004/kelly.pdf

Lee R. D., 1994, “Population Age Structure, Intergenerational Transfer, and Wealth: A New Approach with Applications to the United States.” Journal of Human Resources. Vol. 29, 1027-1063.

2003, "Perspectives on Transfers to Children.” Unpublished paper presented to the Conference on Cross-National Comparisons of Expenditures on Children, Princeton University.

Lietz C. and H. Sutherland, 2005, "Social Indicators and other Income Statistics using EUROMOD: an assessment of the 2001 baseline and changes 1998-2001”, EUROMOD Working Paper (forthcoming)

Mantovani D. and H. Sutherland, 2003, "Social Indicators and other Income Statistics using the EUROMOD Baseline: a Comparison with Eurostat and National Statistics”, EUROMOD Working Paper EM1/03, Microsimulation Unit, Department of Applied Economics, University of Cambridge.

Matsaganis M., C. O’Donoghue, H. Levy, M. Coromaldi, M. Mercader-Prats, C. Farina Rodrigues, S. Toso and P. Tsakloglou, 2004, "Child Poverty and Family Transfers in Southern Europe”, EUROMOD Working Paper EM2/04, Microsimulation Unit, Department of Applied Economics, University of Cambridge. 
Mira d'Ercole M. and M. Förster, 2005, "Income distribution and poverty in OECD countries in the second half of the 1990s" OECD: Directorate for Employment, Labour and Social Affairs, Paris.

OECD, 2004, Benefits and Wages OECD Indicators, 2004 Edition, Paris: OECD

Sutherland H., 2000, “EUROMOD: A tax-benefit model for the European Union”, Transfer, 6 (2) 312-316.

Sutherland H. (ed), 2001, "EUROMOD: an integrated European Benefit-tax model, Final Report”, EUROMOD Working Paper EM9/01, Microsimulation Unit, Department of Applied Economics, University of Cambridge.

UNICEF, 2005, Child Poverty in Rich Countries, 2005, Innocenti Report Card No. 6, UNICEF Innocenti Research Centre, Florence.

Verbist G., 2004, "Redistributive effect and progressivity of taxes. An International Comparison across the EU using EUROMOD”, EUROMOD Working Paper EM5/04, Microsimulation Unit, Department of Applied Economics, University of Cambridge.

Verbist G., 2005, “Replacement Incomes and Taxes: A distributional analysis for the EU-15 countries”, EUROMOD Working Paper EM2/05, Microsimulation Unit, Department of Applied Economics, University of Cambridge. 


\section{Appendix 1}

\section{EUROMOD Datasets}

\begin{tabular}{|c|c|c|c|c|c|}
\hline \multirow[b]{2}{*}{ Country } & \multirow[b]{2}{*}{ Base Dataset for EUROMOD } & \multirow{2}{*}{$\begin{array}{c}\text { Date of } \\
\text { collection }\end{array}$} & \multirow{2}{*}{$\begin{array}{l}\text { Reference time } \\
\text { period for } \\
\text { incomes }\end{array}$} & \multicolumn{2}{|c|}{ Sample size } \\
\hline & & & & households & children \\
\hline Austria & $\begin{array}{l}\text { Austrian version of European Community } \\
\text { Household Panel }\end{array}$ & 1999 & annual 1998 & 2,674 & 1,687 \\
\hline Belgium & Panel Survey on Belgian Households & 1999 & annual 1998 & 3,653 & 2,245 \\
\hline Denmark & European Community Household Panel & 1995 & annual 1994 & 3,215 & 1,666 \\
\hline Finland & Income distribution survey & 2001 & annual 2001 & 10,736 & 7,493 \\
\hline France & Budget de Famille (HBS) & $1994 / 5$ & annual 1993/4 & 11,291 & 7,448 \\
\hline Germany & German Socio-Economic Panel & 2001 & annual 2000 & 7,020 & 3,743 \\
\hline Greece & European Community Household Panel & 1995 & annual 1994 & 5,168 & 3,089 \\
\hline Ireland & Living in Ireland Survey & 1994 & month in 1994 & 4,048 & 4,534 \\
\hline Italy & Survey of Households Income and Wealth & 1996 & annual 1995 & 8,135 & 4,353 \\
\hline Luxembourg & PSELL-2 & 2001 & annual 2000 & 2,431 & 1,426 \\
\hline Netherlands & Sociaal-economisch panelonderzoek & 2000 & annual 1999 & 4,329 & 2,694 \\
\hline Portugal & European Community Household Panel & 2001 & annual 2000 & 4,588 & 2,388 \\
\hline Spain & European Community Household Panel & 2000 & annual 1999 & 5,048 & 2,642 \\
\hline Sweden & Income distribution survey & 1997 & annual 1997 & 19,634 & 8,474 \\
\hline UK & Family Expenditure Survey (HBS) & $2000 / 1$ & month in 2000/1 & 6,634 & 4,071 \\
\hline
\end{tabular}


Appendix 2

Child poverty estimates from EUROMOD, compared with selected estimates from the Luxembourg Income Study and the OECD

Table A2.1 provides a comparison of poverty rates calculated using EUROMOD for incomes in 2001 with estimates using the same definitions and assumptions from the Luxembourg Income Study web site and as calculated by the OECD. ${ }^{36}$ For further discussion of such comparisons see Mantovani and Sutherland (2003) and for a more detailed comparison for 2001 see Lietz and Sutherland (2005). Both sources also provide comparisons with estimates from the European Community Household Panel. While child and overall poverty rates from EUROMOD and the other sources of such calculations are not identical, this can be due to a number of factors, including:

- Precise definitions and treatment of the data (e.g. bottom- coding) may differ. The process of simulation is likely to result in a somewhat less unequal distribution of incomes, due to not taking account of tax evasion and benefit non-take-up. (Even without simulation it is quite common for analysts working on the same data to produce estimates that are not identical. This is apparently the case for the LIS and OECD estimates shown in the table; comparisons of the two sources show it to be the case for some other countries too.)

- The underlying source of data may not be the same. Sampling error, differences in collection and processing methods and in precise variable definitions, re-weighting regimes etc will result in discrepancies between the estimates.

- The date to which the incomes refer may differ (whether or not the underlying source is the same survey). EUROMOD updates the data to the policy year (in this case, 2001) so for many countries the updating process results in the estimates using 2001 policies but original incomes updated from an earlier year. As the table shows, in some countries EUROMOD uses a more recent underlying data source than LIS/OECD. In others it is an older source. On top of this come the potential discrepancies introduced through simulating 2001 policies. In some countries policy reforms between the LIS/OECD data year and 2001 may have changed the relationship between pre- and post- tax and transfer incomes (none of the LIS/OECD sources are more recent than 2001).

\footnotetext{
${ }^{36}$ The choice of which of the two sources to use is made on the same basis as in UNICEF (2005) although in some cases data from both sources are shown.
} 
Interestingly, some of the countries with the largest discrepancies in poverty estimates use the same data in EUROMOD and the other source(s) for the same, recent year involving little or no updating (e.g. Germany, Luxembourg). While others with very similar estimates achieve this with different underlying data sources, involving substantial updating (e.g. Denmark, France, Greece). 
Table A2.1 Child poverty estimates from EUROMOD, compared with estimates from the Luxembourg Income Study and the OECD

\begin{tabular}{|c|c|c|c|c|c|c|c|c|c|c|c|c|c|c|c|}
\hline & $\mathbf{A T}$ & BE & DK & FI & FR & GE & GR & IR & IT & $\mathbf{L U}$ & NL & $\mathbf{P T}$ & SP & SW & UK \\
\hline $\begin{array}{l}\text { Overall poverty rate } \\
\text { EUROMOD “2001” }\end{array}$ & 6.0 & 7.4 & 5.0 & 5.5 & 7.6 & 6.7 & 14.0 & 16.2 & 13.3 & 4.1 & 5.3 & 13.2 & 14.0 & 6.0 & 9.7 \\
\hline $\begin{array}{l}\text { Overall poverty rate LIS } \\
(94-00)\end{array}$ & 8.0 & 8.0 & $\mathrm{n} / \mathrm{a}$ & 5.4 & 8.0 & 8.3 & $\mathrm{n} / \mathrm{a}$ & 16.5 & 12.7 & 6.0 & 7.3 & $\mathrm{n} / \mathrm{a}$ & $\mathrm{n} / \mathrm{a}$ & 6.5 & 12.5 \\
\hline Difference & -2.0 & -1.4 & & +0.1 & -0.4 & -1.6 & & -0.3 & +0.6 & -1.9 & -2.0 & & & -0.5 & -2.8 \\
\hline $\begin{array}{l}\text { Overall poverty rate } \\
\text { OECD (95-01) }\end{array}$ & & & 4.3 & & 7.0 & 9.8 & 13.5 & 15.4 & & & & 13.7 & 11.5 & & \\
\hline Difference & & & +0.7 & & +0.6 & -3.1 & +0.5 & +0.8 & & & & -0.5 & +2.5 & & \\
\hline $\begin{array}{l}\text { Child poverty rate } \\
\text { EUROMOD “2001” }\end{array}$ & 4.5 & 4.7 & 3.0 & 3.2 & 7.9 & 7.1 & 11.5 & 19.0 & 17.2 & 5.2 & 7.2 & 15.5 & 18.5 & 2.5 & 12.1 \\
\hline $\begin{array}{l}\text { Child poverty rate LIS } \\
(94-00)\end{array}$ & 10.2 & 7.7 & $\mathrm{n} / \mathrm{a}$ & 2.8 & 7.9 & 9.0 & $\mathrm{n} / \mathrm{a}$ & 17.2 & 16.6 & 9.1 & 9.8 & $\mathrm{n} / \mathrm{a}$ & $\mathrm{n} / \mathrm{a}$ & 4.2 & 15.4 \\
\hline Difference & -5.7 & -3.0 & & -0.4 & 0.0 & -1.9 & & +1.8 & +0.8 & -3.9 & -2.6 & & & -1.7 & -3.3 \\
\hline $\begin{array}{l}\text { Child poverty rate } \\
\text { OECD }(94-00)\end{array}$ & & & 2.4 & & 7.3 & 10.2 & 12.4 & 15.7 & & & & 15.6 & 13.3 & & \\
\hline Difference & & & +0.6 & & 0.6 & -3.1 & -0.9 & -3.3 & & & & -0.1 & +5.2 & & \\
\hline LIS data source* & $\mathrm{S}, \mathrm{E}$ & $\mathrm{D}, \mathrm{E}$ & $\mathrm{n} / \mathrm{a}$ & $\mathrm{S}, \mathrm{E}$ & S, S & S, E & $\mathrm{n} / \mathrm{a}$ & $\mathrm{D}, \mathrm{L}$ & S, L & S, S & S, S & $\mathrm{n} / \mathrm{a}$ & $\mathrm{n} / \mathrm{a}$ & S, L & $\mathrm{D}, \mathrm{E}$ \\
\hline OECD data source* & & & $\mathrm{D}, \mathrm{L}$ & & $\mathrm{D}, \mathrm{L}$ & S, S & $\mathrm{D}, \mathrm{L}$ & $\mathrm{D}, \mathrm{L}$ & & & & $\mathrm{D}, \mathrm{S}$ & $\mathrm{D}, \mathrm{E}$ & & \\
\hline Date of LIS incomes & 1997 & 1997 & & 2000 & 1994 & 2000 & & 2000 & 2000 & 2000 & 1999 & & & 2000 & 1999 \\
\hline Date of OECD incomes & & & 2000 & & 2000 & 2001 & 1999 & 2000 & & & & 2000 & 1995 & & \\
\hline
\end{tabular}

* S: same data source as EUROMOD; D: different data source than EUROMOD; n/a not available

E: earlier year; L: later year; S: same year.

Sources: EUROMOD (version 28A);Luxembourg Income Study (LIS) Key Figures, accessed at http://www.lisproject.org/keyfigures.htm on 5/1/05; OECD: Mira d’Ercole and Förster (2005) 


\section{Appendix 3: EUROMOD estimates using Eurostat-recommended assumptions}

This appendix provides some key estimates from the paper re-calculated using the modified OECD equivalence scale and (where appropriate) a poverty line of $60 \%$ median household equivalised disposable income. Children are defined as people aged under 18. The modified OECD equivalence scale weights each household as 1 , adding 0.5 for each person additional to the first aged 14 or older and 0.3 for each person aged less than 14 .

Table A3.1: Child poverty rates compared with overall poverty rates in EU15, 2001 (\%)

\begin{tabular}{|c|c|c|c|c|c|c|c|c|c|c|c|c|c|c|c|}
\hline & AT & BE & DK & FI & FR & GE & GR & IR & IT & LU & NL & PT & SP & sw & UK \\
\hline \multicolumn{16}{|c|}{ Square root scale, using $\mathbf{5 0} \%$ median as the poverty line (as in Figure 2 ) } \\
\hline Child poverty rate & 4.5 & 4.7 & 3.0 & 3.2 & 7.9 & 7.1 & 11.5 & 19.0 & 17.2 & 5.2 & 7.2 & 15.5 & 18.5 & 2.5 & 12.1 \\
\hline Overall poverty rate & 6.0 & 7.4 & 5.0 & 5.5 & 7.6 & 6.7 & 14.0 & 16.2 & 13.3 & 4.1 & 5.3 & 13.2 & 14.0 & 6.0 & 9.7 \\
\hline$\underline{\text { Difference }}$ & -1.6 & -2.7 & -2.0 & -2.3 & 0.2 & 0.4 & -2.5 & 2.7 & 3.9 & 1.1 & 1.9 & 2.4 & 4.6 & -3.5 & 2.5 \\
\hline \multicolumn{16}{|c|}{ Modified OECD scale, using $60 \%$ of the median as the poverty line } \\
\hline Child poverty rate & 10.5 & 8.8 & 6.1 & 10.1 & 19.1 & 15.0 & 17.7 & 26.6 & 26.0 & 15.5 & 13.8 & 28.8 & 25.3 & 8.7 & 21.4 \\
\hline Overall poverty rate & 10.2 & 11.4 & 9.8 & 11.1 & 15.6 & 12.4 & 20.0 & 21.8 & 20.6 & 10.2 & 11.8 & 21.6 & 18.9 & 11.9 & 17.1 \\
\hline Difference & 0.3 & -2.7 & -3.7 & -1.0 & 3.6 & 2.6 & -2.3 & 4.8 & 5.5 & 5.3 & 2.0 & 7.2 & 6.4 & -3.2 & 4.3 \\
\hline
\end{tabular}

Table A3.2: Spending on child contingent transfers and tax concessions in EU15 in 2001: per child spending on all children and poor children as a proportion of per-capita household disposable income (\%)

\begin{tabular}{lccccccccccccccc}
\hline & AT & BE & DK & FI & FR & GE & GR & IR & IT & LU & NL & PT & SP & SW & UK \\
\hline All children & 18.8 & 18.7 & 14.0 & 13.6 & 15.3 & 14.5 & 4.9 & 16.1 & 7.0 & 22.8 & 8.4 & 8.0 & 4.4 & 11.8 & 15.5 \\
\hline Poor children & \multicolumn{8}{c}{ Square root scale, using } & $\mathbf{5 0 \%}$ median as the poverty line (as in Figure 7) \\
& 21.4 & 17.7 & 17.8 & 17.7 & 17.0 & 20.8 & 2.7 & 27.2 & 7.4 & 17.0 & 11.9 & 11.0 & 3.1 & 10.3 & 22.8 \\
& \multicolumn{8}{c}{ Modified OECD scale, using } & $\mathbf{6 0 \%}$ of the median as the poverty line \\
& 20.5 & 19.1 & 17.9 & 17.2 & 18.1 & 20.0 & 3.2 & 23.8 & 9.0 & 19.2 & 10.4 & 11.3 & 3.1 & 14.2 & 23.2 \\
\hline
\end{tabular}

Source: EUROMOD

See Figure 5

Table A3.3 Child poverty rates in EU15 in 2001, with and without child-contingent incomes, all transfers, and transfers and taxes (\%)

\begin{tabular}{|c|c|c|c|c|c|c|c|c|c|c|c|c|c|c|c|}
\hline & AT & $\mathrm{BE}$ & DK & $\mathrm{FI}$ & FR & GE & GR & IR & IT & LU & NL & PT & SP & sw & UK \\
\hline \multicolumn{16}{|c|}{ Square root scale, using $\mathbf{5 0 \%}$ median as the poverty line (as in Figure $\mathbf{8 a}$ and 12 ) } \\
\hline Baseline & 4.5 & 4.7 & 3.0 & 3.2 & 7.9 & 7.1 & 11.5 & 19.0 & 17.2 & 5.2 & 7.2 & 15.5 & 18.5 & 2.5 & 12.1 \\
\hline Without child-contingent incomes & 15.2 & 14.2 & 10.9 & 16.2 & 22.3 & 17.9 & 13.3 & 27.8 & 25.3 & 23.1 & 13.3 & 24.1 & 20.3 & 13.9 & 30.5 \\
\hline Without all transfers & 25.0 & 22.1 & 25.7 & 24.8 & 28.3 & 22.5 & 18.5 & 32.3 & 30.3 & 28.1 & 17.1 & 30.9 & 26.8 & 31.3 & 36.0 \\
\hline Without all transfers and taxes & 14.3 & 13.5 & 13.4 & 15.5 & 19.8 & 16.2 & 13.8 & 27.5 & 21.0 & 20.3 & 10.2 & 25.7 & 20.1 & 18.4 & 31.4 \\
\hline \multicolumn{16}{|c|}{ Modified OECD scale, using $60 \%$ of the median as the poverty line } \\
\hline Baseline & 10.5 & 8.8 & 6.1 & 10.1 & 19.1 & 15.0 & 17.7 & 26.6 & 26.0 & 15.5 & 13.8 & 28.8 & 25.3 & 8.7 & 21.4 \\
\hline Without child-contingent incomes & 27.4 & 21.7 & 15.5 & 24.6 & 31.6 & 28.3 & 19.7 & 34.3 & 33.5 & 31.9 & 21.8 & 32.0 & 26.3 & 21.7 & 38.7 \\
\hline Without all transfers & 38.2 & 30.7 & 31.6 & 33.1 & 38.0 & 33.1 & 24.6 & 38.6 & 37.8 & 37.5 & 25.0 & 40.2 & 34.6 & 39.2 & 42.0 \\
\hline Without all transfers and taxes & 20.3 & 16.6 & 15.9 & 20.7 & 25.9 & 20.9 & 18.4 & 33.3 & 27.0 & 27.2 & 13.6 & 33.4 & 27.9 & 20.8 & 34.8 \\
\hline
\end{tabular}


Figure A3a: Equivalised household income with and without children and childcontingent incomes in EU15 in 2001: all households with children (PPP-adjusted euro per year)

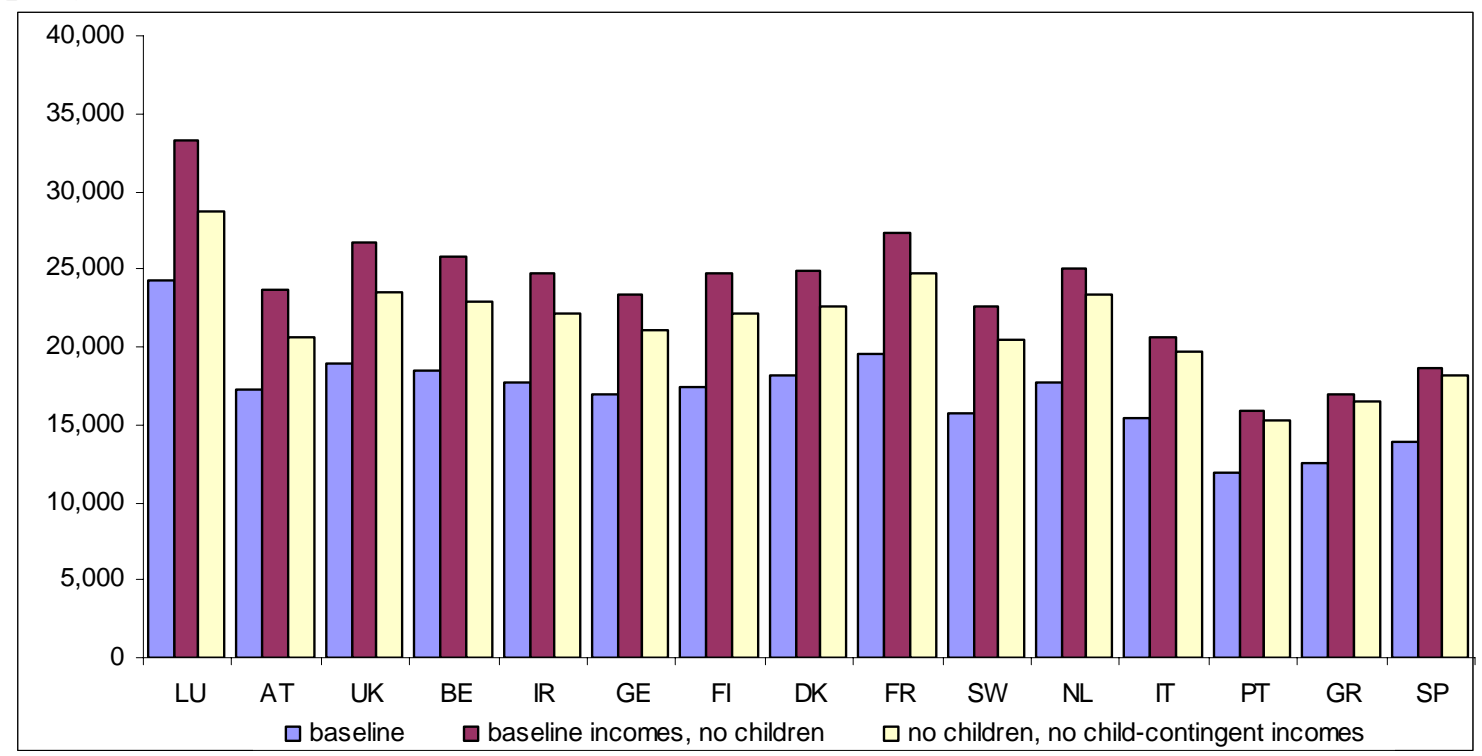

Source: Calculations by authors using EUROMOD version 28A.

Uses the Modified OECD equivalence scale. See Figure 4a which uses the square root equivalence scale 


\section{Appendix 4: Details of child-contingent tax and transfer components and their relative importance, by country}

The following tables show the elements of each national tax and transfer system that are affected by the presence of children aged under 18 in the household. If children are ignored in the calculation of tax liabilities and transfer entitlements these are the elements of the system that change in aggregate. In some cases the change shown is the net effect of several influences. For example a housing benefit may contribute to child-contingent incomes because it contains extra allowances for the presence of children. On the other hand, housing benefit entitlement may rise if other benefits are reduced. The net effect may be positive or negative for any particular household, and in aggregate.

The contribution of particular instruments to the total change is shown, with a decrease in taxes and increase in benefits (due to the disregarding of children) given as positive contribution (to child contingent incomes). Instruments are generally not shown if the effect is less than $0.1 \%$. The percentages may therefore not add to exactly 100 .

\begin{tabular}{|c|c|}
\hline AUSTRIA & $\begin{array}{l}\% \text { of total change in } \\
\text { taxes and benefits }\end{array}$ \\
\hline national income tax & 29.53 \\
\hline child bonus for pensioners (kinderzuschuss (asvg)) & 0.66 \\
\hline family allowance (familienbeihilfe) & 65.45 \\
\hline new born health check bonus (mutter-kind-pass-bonus) & 0.16 \\
\hline provincial family bonus (familienzuschuss der bundeslaender) & 1.15 \\
\hline child care benefit kaernten (kaerntner kinderbetreuungsgeld) & 0.62 \\
\hline social assistance (sozialhilfe) & 0.31 \\
\hline small children benefit (kleinkindbeihilfe) & 0.03 \\
\hline unemployment payment (arbeitslosengeld) & 0.04 \\
\hline student payments & 0.65 \\
\hline \multirow[t]{2}{*}{ housing benefit } & 0.97 \\
\hline & 100.00 \\
\hline BELGIUM & $\begin{array}{l}\% \text { of total change in } \\
\text { taxes and benefits }\end{array}$ \\
\hline national income tax & 22.72 \\
\hline wealth or national property taxes & 1.28 \\
\hline child benefit & 72.67 \\
\hline child birth benefit & 0.86 \\
\hline income support (minimex) & 2.09 \\
\hline Short-sickness allocation & 0.10 \\
\hline \multirow[t]{2}{*}{ Young unemployed alloc. } & 0.25 \\
\hline & 100.00 \\
\hline DENMARK & $\begin{array}{l}\% \text { of total change in } \\
\text { taxes and benefits }\end{array}$ \\
\hline bottom national income tax & -0.56 \\
\hline local income tax (incl. av. county, municipal and church tax) & -3.00 \\
\hline middle national income tax & -0.30 \\
\hline top national income tax & 0.15 \\
\hline housing benefit & 7.09 \\
\hline child benefit (incl. ordinary, extra, special and multi cb) & 16.12 \\
\hline day care subsidy & 7.31 \\
\hline family allowance & 66.93 \\
\hline housing allowance & -0.06 \\
\hline \multirow[t]{2}{*}{ social assistance } & 6.29 \\
\hline & 100.00 \\
\hline
\end{tabular}




\begin{tabular}{|c|c|}
\hline FINLAND & $\begin{array}{c}\% \text { of total change in } \\
\text { taxes and benefits }\end{array}$ \\
\hline national income tax & -0.94 \\
\hline wealth or nat.property taxes & -0.23 \\
\hline church taxation & -0.27 \\
\hline deposit interest taxation & -0.16 \\
\hline municipal taxation & -4.43 \\
\hline housing benefit & 5.58 \\
\hline student payments & 0.33 \\
\hline other irregular lump sum benefits & 0.46 \\
\hline maternity payments & 17.63 \\
\hline home child care benefit & 68.74 \\
\hline child benefit & 2.90 \\
\hline lone parent child benefit & 1.47 \\
\hline social assistance benefit & 0.32 \\
\hline basic unemployment benefit & 3.03 \\
\hline earnings related unemployment benefit & 1.12 \\
\hline labour market support & -0.94 \\
\hline \multirow[t]{2}{*}{ gross state pension income } & -0.23 \\
\hline & 100.00 \\
\hline FRANCE & $\begin{array}{l}\text { \% of total change in } \\
\text { taxes and benefits }\end{array}$ \\
\hline national income tax & 24.97 \\
\hline french tax credit & 0.86 \\
\hline student payments & 0.84 \\
\hline allocation familial & 44.12 \\
\hline family benefit for young children (apje) & 8.80 \\
\hline allocation de rentrèe scolaire & 5.95 \\
\hline family benefit for many children & 5.44 \\
\hline allocation logement & 6.66 \\
\hline allocation de parent isolé & 2.95 \\
\hline \multirow[t]{2}{*}{ revenu minimum d'insertion } & -0.67 \\
\hline & 100.00 \\
\hline GERMANY & $\begin{array}{l}\% \text { of total change in } \\
\text { taxes and benefits }\end{array}$ \\
\hline national income tax & 4.84 \\
\hline solidarity surplus & 0.27 \\
\hline housing benefit & 6.23 \\
\hline student payments & 0.10 \\
\hline child benefit & 78.05 \\
\hline federal child raising benefit (bundeserziehungsgeld) & 3.64 \\
\hline direct housing support (wohneigentumsfoerderung/eigenheimzul.gesetz) & 3.96 \\
\hline post natal benefit for non-earning mothers (entbindungsgeld) & 0.05 \\
\hline provincial child raising benefit (landeserziehungsgeld) & 0.72 \\
\hline social assistence (sozialhilfe) & 1.79 \\
\hline \multirow[t]{2}{*}{ nursing home insurance payment (pflegeversicherung) } & 0.31 \\
\hline & 100.00 \\
\hline
\end{tabular}




\begin{tabular}{|c|c|}
\hline GREECE & $\begin{array}{l}\% \text { of total change in } \\
\text { taxes and benefits }\end{array}$ \\
\hline national income tax & 12.79 \\
\hline OAED child allowance & 13.73 \\
\hline large family benefit & 6.07 \\
\hline third child benefit & 8.02 \\
\hline unprotected child benefit & 3.43 \\
\hline civil servant child allowance & 30.00 \\
\hline EKAS social solidarity benefit & -0.21 \\
\hline old age pension & 19.32 \\
\hline invalidity pension & 1.83 \\
\hline survivor's pension & 3.38 \\
\hline \multirow[t]{2}{*}{ unemployment benefit } & 1.05 \\
\hline & 100.00 \\
\hline IRELAND & $\begin{array}{l}\% \text { of total change in } \\
\text { taxes and benefits }\end{array}$ \\
\hline national income tax & 2.09 \\
\hline housing benefit & -0.63 \\
\hline child benefit & 54.42 \\
\hline disability benefit & 1.04 \\
\hline disabled persons maintenance allowance & 0.81 \\
\hline deserted wife allowance & -0.64 \\
\hline deserted wife benefit & 0.68 \\
\hline family income supplement & 1.72 \\
\hline home carers tax credit & 9.78 \\
\hline invalidity pension & 0.59 \\
\hline lone parent allowance & 25.90 \\
\hline unemployment assistance (It) & 1.43 \\
\hline survivors benefit & 0.49 \\
\hline unemployment assistance (st) & 1.11 \\
\hline \multirow[t]{2}{*}{ unemployment benefit } & 0.92 \\
\hline & 100.00 \\
\hline ITALY & $\begin{array}{l}\% \text { of total change in } \\
\text { taxes and benefits }\end{array}$ \\
\hline national and local income tax (irpef) & 40.57 \\
\hline student payments & 0.11 \\
\hline family allowance 1 adult, plus children & 3.73 \\
\hline family allowance 2 adult, no children & -6.95 \\
\hline family allowance 2 adults plus children & 61.23 \\
\hline social security: regional administrations & 0.24 \\
\hline social security: provincial administration & 0.59 \\
\hline \multirow[t]{2}{*}{ social security: municipal administration } & 0.34 \\
\hline & 100.00 \\
\hline LUXEMBOURG & $\begin{array}{l}\% \text { of total change in } \\
\text { taxes and benefits }\end{array}$ \\
\hline national income tax & 18.77 \\
\hline child benefit (family benefit) & 60.22 \\
\hline prenatal-, postnatal-, and child birth allowance & 1.93 \\
\hline education allowance (allocation d'éducation) & 11.77 \\
\hline maternity allowance (allocation de maternité) & 1.69 \\
\hline social assistence (minimum income) & 0.90 \\
\hline beginning of school allowance (allocation de rentrée scolaire) & 3.52 \\
\hline \multirow[t]{2}{*}{ orphan allowance } & 1.16 \\
\hline & 100.00 \\
\hline
\end{tabular}




\begin{tabular}{|c|c|}
\hline NETHERLANDS & $\begin{array}{l}\% \text { of total change in } \\
\text { taxes and benefits }\end{array}$ \\
\hline national income tax & 7.11 \\
\hline housing benefit & 1.36 \\
\hline child benefit & 84.43 \\
\hline social assistance for unemployed 50-64 and disabled, and unemployed $<64$ with children & 1.09 \\
\hline general social assistance for families with children & 24.25 \\
\hline social assistance for unemployed 50-64 and disabled, and unemployed $<64$ without children & -1.04 \\
\hline general social assistance for families without children & -19.73 \\
\hline \multirow[t]{2}{*}{ survivors' benefit (anw) (formerly widow benefit) } & 2.44 \\
\hline & 100.00 \\
\hline PORTUGAL & $\begin{array}{l}\% \text { of total change in } \\
\text { taxes and benefits }\end{array}$ \\
\hline capital income taxes & -0.43 \\
\hline income tax & 22.92 \\
\hline child benefits & 60.09 \\
\hline income supplement to ensure minimum income & 16.78 \\
\hline survivors related benefits & 0.26 \\
\hline \multirow[t]{2}{*}{ family benefits } & 0.05 \\
\hline & 100.00 \\
\hline SPAIN & $\begin{array}{l}\% \text { of total change in } \\
\text { taxes and benefits }\end{array}$ \\
\hline national income tax & 84.20 \\
\hline housing benefits & 0.16 \\
\hline child social assistance & 12.73 \\
\hline sickness and invalidity benefit & 0.31 \\
\hline social assistance benefits (household sa excluding child benefit) & 0.16 \\
\hline \multirow[t]{2}{*}{ family benefits } & 2.41 \\
\hline & 100.00 \\
\hline SWEDEN & $\begin{array}{l}\% \text { of total change in } \\
\text { taxes and benefits }\end{array}$ \\
\hline local income taxes & -0.88 \\
\hline net national income tax & -0.13 \\
\hline net tax on wealth & -1.02 \\
\hline child benefits & 74.31 \\
\hline housing benefits & 18.74 \\
\hline housing benefit suppl. for pensioners & -0.48 \\
\hline social assistance & 4.09 \\
\hline other taxable pensions & 1.52 \\
\hline non-taxable pension & 1.34 \\
\hline \multirow[t]{2}{*}{ study grants for high school } & 2.63 \\
\hline & 100.00 \\
\hline UK & $\begin{array}{l}\% \text { of total change in } \\
\text { taxes and benefits }\end{array}$ \\
\hline national income tax & 11.33 \\
\hline housing benefit & 0.29 \\
\hline student payments & 0.19 \\
\hline child benefit & 46.03 \\
\hline council tax benefit & 0.04 \\
\hline working family tax credit & 16.62 \\
\hline income support & 24.20 \\
\hline \multirow[t]{2}{*}{ training allowance } & 1.21 \\
\hline & 100.00 \\
\hline
\end{tabular}

